\title{
EL COMUNISMO MEXICANO Y LA LUCHA POR LA PAZ EN LOS INICIOS DE LA GUERRA FRÍA
}

\author{
Horacio Crespo \\ Universidad Autónoma del Estado de Morelos
}

La lucha contra la guerra es nuestra tarea central, es la primera tarea del Partido.

Pleno del Comité Central del Partido

Comunista Mexicano, octubre de 1949.

\begin{abstract}
A partir de fines de 1947, el Partido Comunista MexicaA no (РСM) asumió la emergente confrontación entre dos bloques antagónicos en el escenario internacional - conocida luego como Guerra Fría - con una política articulada esencialmente en torno a la lucha en defensa de la paz, en favor del desarme y de la coexistencia pacífica entre diferentes regímenes sociales. A partir de este punto nodal el comunismo mexicano propuso - con muchas dificultades y poco eco- la conformación en México de un amplio frente
\end{abstract}

Fecha de recepción: 14 de enero de 2016

Fecha de aceptación: 3 de febrero de 2016 
de masas en defensa de la paz, la democracia y la independencia nacional de cara a las crecientes presiones económicas y políticas del "imperialismo yanqui" y sus asociados. Paulatinamente, el partido comunista fue distanciándose del régimen del presidente Miguel Alemán hasta la ruptura insinuada a fines de 1949 y asumida abiertamente por el XI Congreso partidario en noviembre de 1950, argumentando su claudicación frente a las exigencias de Estados Unidos y el abandono y la traición a las postulaciones fundamentales de la "revolución burguesa", a la que había dejado de representar. La política del PCM siguió a pie juntillas en todo este periodo inicial de la Guerra Fría las orientaciones elaboradas por el régimen soviético por medio de la Kominform (Oficina de Información de los Partidos Comunistas y Obreros, disuelta en 1956), que daban un valor estratégico al Movimiento de los Pueblos por la Paz en su interés por frenar lo que advertía como intenciones belicistas y agresivas del bloque conducido por Estados Unidos.

El PCM (hasta 1943 Partido Comunista de México) atravesó entre 1940 y 1960 una etapa difícil, acosado por el Estado y sacudido por los cambios del escenario mundial posterior a la guerra y del movimiento comunista internacional luego de la muerte de Stalin en 1953. Se ha caracterizado a los años 1940-1962 del PCM como un periodo de "discordia, desunión y declinación"; como prueba de ello en ese periodo sus efectivos pasaron de 30000 a 2 o $3000 .{ }^{1}$ Para los años 1946-1950 otro autor también tiene un juicio lapidario: "embarcado en una política completamente errática, la pérdida de independencia política y la confusión ideológica

${ }^{1}$ Schmitт, Communism, p. 19. 
condujeron al Partido Comunista Mexicano a cometer errores gravísimos". ${ }^{2}$ Los comienzos de la Guerra Fría lo encontraron debilitado y desorientado, con una dirección cuestionada, trabajando en colaboración con el naciente Partido Popular animado por Lombardo Toledano, pero en dura competencia con el grupo marxista El Insurgente y con Acción Socialista Unificada, nutridos por muchos de sus antiguos dirigentes y militantes expulsados y, a partir de 1950, con el Partido Obrero y Campesino de México. ${ }^{3}$ En materia internacional los tres partidos - $\mathrm{PCM}$, Popular, $\mathrm{y}$ Obrero y Campesino - siguieron inquebrantablemente la línea soviética.

El Congreso Extraordinario del partido reunido en marzo de 1940 había marcado el inicio de una crisis que duró dos décadas. Como señaló Gerardo Unzueta hace más de 30 años, se trató de una crisis partidaria superpuesta a la sufrida por todo el movimiento revolucionario mexicano, suscitada por el agotamiento del ímpetu reformista del cardenismo, la pérdida de autonomía de la clase obrera y de los campesinos frente al Estado, y la recuperación de la capacidad de respuesta de los grupos reaccionarios por dinámicas en las que la Guerra Fría jugó un papel significativo. Para reavivar la perspectiva revolucionaria frente a ese complejo cambio de situación era necesario - afirma Unzueta - redefinir la vinculación del proletariado con las fuerzas que conducían el proceso político del país, para lo que el PCM debía elaborar un "nuevo proyecto general y global" centrado en su

\footnotetext{
2 Peláez Ramos, "Guerra fría”, p. 1.

${ }^{3}$ Mesa, passim; Millon, Lombardo Toledano, cap. VIII; Alonso, En busca.
} 
propio desarrollo político y teórico, en consolidar la unidad de la clase obrera, desarrollar y fortalecer la autonomía de las organizaciones obreras y populares, y revisar la subordinación acrítica del PCM a la Comintern. No existían condiciones ni ideas que diesen vida a ese proyecto $y$, en consecuencia, la crisis se prolongó a lo largo de los siguientes 20 años. ${ }^{4}$

Cuestiones como el carácter de la revolución mexicana, la naturaleza del grupo gobernante, el grado de desarrollo del país, el movimiento sindical y su relación con el Estado, la cuestión agraria y la perspectiva de la alianza política entre obreros y campesinos, eran decisivas y necesarias de ser de nuevo debatidas y comprendidas. Y, fundamentalmente, la estrategia leninista de la hegemonía del proletariado en el proceso revolucionario nunca fue bien comprendida y mucho menos aplicada por el PCM, y a finales de los años cincuenta será señalada como la cuestión crucial eludida, no

${ }^{4}$ Unzueta, "Crisis", p. 193. El autor, nacido en Tampico en 1925, fue un veterano militante del PCM, al que ingresó en 1946. Director editorial de La Voz de México en los momentos del "charrazo" sindical en 1948, fue secuestrado como parte de la represión a la izquierda. Desde1957 se opuso a la dirección de Dionisio Encina en el grupo encabezado por Martínez Verdugo y Pérez Gaytán. Por esta razón en 1958 la dirección del partido lo retiró del comité editorial de La Voz de México, al año siguiente fue reinstalado y entrevistó para el periódico al Che Guevara y a Camilo Cienfuegos. Entre 1960 y 1963 de nuevo fue editor de la publicación comunista. En pleno movimiento estudiantil, siendo secretario del Comité partidario del D.F., fue detenido en julio de 1968 y condenado a 8 años de cárcel. Salió en libertad en diciembre de 1971. Miembro del Comité Central del PCM y diputado federal por ese partido entre 1979 y 1982 , siguió en el PCM hasta su disolución en 1981. Ensayista y novelista. Véase Almomento Noticias, "Realizan homenaje al periodista y escritor Gerardo Unzueta", 31 de enero de 2014, http://www.almomento.mx/. Consulta 10 de enero de 2016; De Pablo Hammeken, "Unzueta”. 
resuelta, en la coyuntura de 1940 y en los años siguientes. La discusión de la naturaleza de esa prolongada crisis del PCM fue un tema central en la renovación política consumada en el XIII Congreso partidario de 1960 - en el contexto del triunfo de la revolución cubana - , y ella misma insumió bastante tiempo. La convocatoria al Congreso en 1959 lo señaló explícitamente:

El XIII Congreso Nacional deberá caracterizarse por la lucha contra el dogmatismo y el sectarismo, que durante toda la historia de nuestro partido han sido factores determinantes en el mantenimiento de su estrechez y debilidad, contra el revisionismo del marxismo, expresión teórica del oportunismo de derecha y que representa la ideología burguesa disfrazada de marxismo-leninismo, y contra todas las manifestaciones concretas del oportunismo de derecha que se mantienen en la política del Partido. El XIII Congreso tiene la gran tarea de [...] construir un verdadero Partido marxista leninista del proletariado mexicano. [Para esto] El examen de la situación del Partido debe abarcar los últimos 19 años de su vida. ${ }^{5}$

El informe del secretario general Dionisio Encina al Pleno del Comité Central de diciembre de 1956 había abordado por primera vez con algún atisbo de autocrítica la sensible cuestión de las expulsiones de dirigentes en la década de 1940, de las que era absoluto responsable. ${ }^{6}$ Es significativo que la decisión de revisar ese periodo de la historia del partido fuese adoptada, a pesar de la resistencia y vacilaciones de la dirección, en la reunión del Comité Central dedicada a la

${ }^{5}$ Comisión, Boletín, pp. 112, 113.

${ }^{6}$ Encina, Sobre la situación, pp. 95-96, 115. 
discusión de lo ocurrido en abril de 1956, durante el transcurso del XX Congreso del Partido Comunista de la Unión Soviética (PCUs) - inicio de la "desestalinización" con el "informe secreto" de Nikita Jruschov-, y adoptada como el comienzo de la regeneración partidaria, contra la línea y la dirección de Encina. A tal punto esto fue percibido así por los militantes del PCM que Unzueta lo señala como un "verdadero deshielo", aludiendo al término utilizado para designar el periodo de crítica jruschoviana al estalinismo en el Pcus a partir del XX Congreso. Se dio también en el marco de ascenso de luchas obreras y populares desde 1956 que impulsaron decisivamente esa renovación. ${ }^{7}$ El resultado del trabajo de la comisión creada con esa finalidad en el Pleno mencionado, dirigida por Manuel Terrazas, ${ }^{8}$ es un importante documento sobre la historia del partido, centrado en la lucha de líneas en ese periodo y en la expulsión de dirigentes

7 Unzueta, “Crisis”, pp. 221-222, 230-231, 238; MÉndez, “Por la renovación”, pp. 244, 246-259.

8 Manuel Terrazas Guerrero (1923-2010). Maestro. Siendo normalista, ingresó al PCM en la década de 1940. En 1947 fue apresado en Monterrey. Fue editor de La Voz de México, junto con Gerardo Unzueta, y secuestrado con él por la policía en diciembre de 1948. En 1956, representando al PCM, asistió al XX Congreso del pCUs. En 1958 participó, con Unzueta y Martínez Verdugo, en la oposición interna a la dirección de Encina, por lo que en noviembre fue destituido del consejo editorial de La Voz de México. A partir del XIII Congreso del Рсм (1960) participó en la dirección del partido. En 1961 representó al РCM en la dirigencia del Movimiento de Liberación Nacional de Cárdenas. En abril de 1965 fue detenido en un local del partido en el D. F. En 1973 dirigió, junto con F. Cortés y E. Jardón, una escisión izquierdista del PCM, la Unidad de Izquierda Comunista, que se aproximó a Sánchez Cárdenas y a Velasco. En 1982 estuvo entre los fundadores del Partido Socialista Unificado de México. Al final de su vida presidió el Movimiento Mexicano por la Paz. Véase De Pablo Hammeken, “Terrazas”, s. p. 
por la dirección de Encina, y fue aprobado por el Pleno del Comité Central de mayo de 1957. No es ocioso señalar - por las implicaciones políticas que conllevaba, y porque en el mundo cerrado de los códigos comunistas se prestaba mucha atención a estos indicios - que la metodología seguida en el análisis de la lucha interna fue tomada de las indicaciones de Mao Tse-tung acerca de los conflictos de los comunistas chinos entre 1930 y 1934, y no menciona nunca a Stalin, omnipresente años atrás. ${ }^{9}$

En resumen, se señalaron tres etapas en este proceso: 1940, 1943 y 1947-1948. La primera en el Congreso Extraordinario del Partido, en mayo de 1940, en el cual se revisaron las tendencias denominadas "sectario-oportunistas" expresadas en el IV Consejo Nacional de la Confederación de Trabajadores de México (СтM) en 1937, primero al dividir la central obrera y luego con su corrección al fijar la línea de “ $i U n i d a d$ a toda costa!” adoptada por presión de Earl Browder, entonces poderoso secretario del Partido Comunista de Estados Unidos (PCUSA), amigo de Lombardo Toledano, política que entregó todas las posiciones de dirección en la Стм a la camarilla lombardista, congregada especialmente en torno de Fidel Velázquez. Se inició así el largo derrumbe del PCM en el movimiento obrero mexicano, fruto de la presión del Estado y sus personeros, pero también, y fundamentalmente, de una estrategia sindical equivocada y una larga serie de graves errores

\footnotetext{
9 Comité, La lucha. La cita de Mao, p. 14. Es llamativo que la figura y los elogios a Stalin ya estuviesen atemperados en el XII Congreso del PCM realizado en septiembre de 1954, aunque no habían desaparecido por completo, lo que indica la "sensibilidad" de Encina a los vientos políticos que corrían en el Kremlin moscovita.
} 
tácticos, que culminaron con el "charrazo" de $1948 .{ }^{10}$ En el Congreso Extraordinario - en el que estaban presentes James Ford, del PCuSA, Leon Haikiss ${ }^{11}$ y Victorio Codovilla, ${ }^{12}$ por la Comintern, encargándose este último del manejo de la situación y la selección de la nueva dirección - se acusó a Hernán Laborde y Valentín Campa de corrupción por aceptar subsidios gubernamentales y de "desviación de derecha", pero el cargo oculto fundamental habría sido que se opusieron al

10 Peláez Ramos, “Guerra fría”. Para 1947 y 1948, se dice en la resolución de 1957 acerca de la lucha interna en el Partido: "Durante el periodo inmediatamente anterior al X Congreso y en el Congreso mismo, debido a esa línea incorrecta [que la situó a la cola de la burguesía] el Partido registraba una notable pérdida de influencia en importantes sectores de la clase obrera. Algunas posiciones que se mantenían en el movimiento sindical se perdieron y no se formulaba ni se aplicaba en esa época una táctica acertada para la labor de los comunistas en los sindicatos y con relación al movimiento obrero. Siguió acentuándose la débil situación orgánica del Partido"; Comité, La lucha, p. 66.

${ }^{11}$ James W. Ford. Afroamericano, obrero siderúrgico, candidato para vicepresidente de Estados Unidos por el pcusa en tres ocasiones, en una fórmula con William Z. Foster para presidente en 1932, y con Browder en 1936 y 1940; RYAN, Earl Browder, pp. 43, 132, 189; León Haikiss es un militante poco conocido, posiblemente agente de la GPU; participó en la represión del poum en Cataluña en 1937-1938 y se indica que también lo hizo Codovilla (véase Tarcus, Diccionario, p. 138), con quien es posible que haya viajado a México en 1940, en relación con el planeamiento de un atentado contra Trostki (TARcus, Diccionario, p. 139). La información respecto a Haikiss, la GPU y el poum en GuTIÉrrez, Algunas notas, p. 8. 12 Victorio Codovilla Ferrandi (1894-1970). Italiano, emigró a Argentina en 1912. Uno de los fundadores del Partido Comunista de Argentina (PCA) y uno de sus principales dirigentes. Desde 1941 hasta su muerte dirigió el PCA. Hizo una larga carrera en la Comintern en las décadas de 1920 y 1930. Hombre de confianza de los dirigentes soviéticos de la época estalinista y también de la posterior, entre 1939 y 1940 estuvo en México a la cabeza de una delegación de la Comintern para "purificar" el PCM. Véase TARcus, Diccionario, pp. 136-142; JEIFETS, JEIFETS y Huber, La Internacional, pp. 77-79. 
planeado atentado de la GPU contra Trotski. ${ }^{13}$ Se hizo la crítica de estas posiciones, se expulsó del partido a Laborde y a Campa y se nombró a la dirección encabezada por Dionisio Encina como secretario general. Hubo luego una serie de expulsiones en masa en el Estado de México, Oaxaca, Veracruz y la desorganización del PCM se expandió a Guerrero, Puebla, Chiapas y otras regiones.

La segunda etapa de la crisis interna del PCM, la de 1943, fue protagonizada por la disidencia favorable a una vinculación más estrecha con Lombardo Toledano y a aceptar su dirección política, integrada por Ángel Oliva Solís, Enrique Ramírez y Ramírez, Miguel Ángel Velasco y Genaro Carnero Checa, miembros del Comité Central, quienes fueron expulsados en octubre de 1943. La tercera etapa de la desintegradora lucha interna se produjo por las críticas a "los errores e insuficiencias de la actividad de la dirección" por parte de cuadros importantes del Partido, como Carlos Sánchez Cárdenas, Miguel Arroche Parra y Alberto Lumbreras, y por diferencias en torno a la caracterización del gobierno de Miguel Alemán, la posición frente al Partido Popular y Lombardo Toledano, y la actitud respecto a grupos marxistas ajenos al partido y a los expulsados del PCM. ${ }^{14}$ Todos ellos también fueron despedidos.

\section{EL CONTEXTO: LA GUERRA FRÍA}

La querella surgida entre los aliados victoriosos en la segunda guerra mundial se tejió en torno de la futura configuración de

${ }_{13}$ Esta versión la da Campa, quien también refiere las intrigas, maniobras y manipulaciones de Codovilla antes y en el Congreso Extraordinario; véase CAMPA, Mi testimonio, pp. 159-166.

${ }^{14}$ Сомiт́́, La lucha, pp. 59-72. 
Alemania y los regímenes políticos de los países de Europa central y oriental fronterizos con la Unión Soviética. El principal objetivo exterior de la URSS en 1945 no era el dominio mundial del comunismo ni tampoco en la "esfera de influencia" delineada por la penetración de sus ejércitos hasta Berlín, tal como lo planteó la propaganda occidental desde el año siguiente. La estrategia inicial dibujada por Stalin era la de una Alemania que no entrañase un peligro potencial para la URSS y la creación de un creíble espacio de protección de sus fronteras occidentales con sistemas políticos confiables en los países vecinos, no necesariamente dominados por los comunistas locales, aunque sus formas no estaban definidas claramente. ${ }^{15}$ Todos los estados fronterizos, con

${ }^{15}$ El caso de Finlandia es ilustrativo de que un neutralismo estricto y una marcada distancia de las presiones occidentales (en especial de Estados Unidos, Gran Bretaña y, posteriormente, de la República Federal Alemana) fue una alternativa posible a la satelización y hegemonismo de la URSS con sus vecinos. La política exterior de Helsinki a partir del fin de la segunda guerra mundial fue vigilada estrechamente por Moscú, sin ocupación militar ni un gobierno dominado por los comunistas, manteniendo distancia respecto de la OTAN (la alianza militar del Atlántico Norte) y sin adhesión al Pacto de Varsovia. En materia económica el país no aceptó el Plan Marshall ni entró al Consejo de Ayuda Mutua Económica (CAME), la zona comercial de los países socialistas. Las relaciones entre Finlandia y la URSS fueron reguladas por un tratado de asistencia, cooperación y ayuda mutua firmado el 6 de abril de 1948. Este delicado equilibrio en la tutela soviética sobre la estricta política exterior de neutralidad e independencia en los asuntos interiores fue denominado despectivamente por algunos sectores occidentales como "finlandización" y caracterizado como "servilismo" hacia Moscú; el término en la actualidad designa procesos de recortes de la soberanía política de un Estado por presiones de un poder exterior. Otros historiadores, por el contrario, aceptan que fue una lúcida muestra de realismo frente a imperativos geoestratégicos, practicada tanto por los líderes de Helsinki como por el Kremlin. Los 
apreciables diferencias, habían sido hostiles a los soviéticos desde los años veinte; Hungría, Rumania y Finlandia fueron aliados de Hitler en la invasión a la URSS en 1941, mientras que Bulgaria se mantuvo no beligerante. Con el terrible precio pagado por la invasión alemana, la dura negociación de Stalin con sus socios de la Gran Alianza en Teherán y Yalta tenía el claro objetivo de su seguridad futura.

Las prevenciones entre los socios de la coalición antihitleriana estaban planteadas desde 1941 y se acrecentaron cuando se hizo evidente el derrumbe militar alemán, desde inicios de 1944. Churchill se mostró activo en diseñar planes para bloquear el avance de los soviéticos en Europa oriental y central con una intervención en los Balcanes, pero el presidente Roosevelt se apegó a la estrategia del segundo frente occidental acordado en Teherán en 1943. El primer ministro inglés intentó, sin mayor éxito, instaurar gobiernos pro occidentales en Europa oriental, y Polonia fue el punto de fricción más tenso y el fracaso más sensible. También quiso negociar esferas de influencia de las potencias, tal como hizo en Moscú en octubre de 1944. En Yalta se avanzó sobre la idea del desmembramiento de Alemania y se negoció acerca de las reparaciones de guerra, pero no hubo arreglos

dirigentes y la prensa finlandesa ejercieron una discreta autocensura en relación con sus diferencias y críticas respecto de la URSS y sus aliados; pero la economía era capitalista, los ciudadanos ejercieron plenamente sus derechos a la diversidad política, social, cultural, religiosa y de libertad de movimientos en el interior y hacia el exterior; también un ejercicio sin restricciones de la democracia parlamentaria pluripartidista. Austria, país no fronterizo con la URSS, luego del fin de la ocupación militar cuatripartita de las potencias vencedoras en 1955 y con el advenimiento de la independencia plena, sostuvo la neutralidad al igual que Finlandia, aunque no se planteó la "tutela” soviética como en el país nórdico. 
concretos al respecto. Finalmente, se consolidó el acuerdo sobre la integración de las Naciones Unidas y se desarrollaron otras complejas tratativas - sin conclusiones firmes en la mayor parte de ellas - en torno a las pretensiones soviéticas sobre territorios japoneses, su presencia hegemónica en Mongolia, sus ambiciones respecto de Manchuria, el problema de los estrechos turcos y las tropas estacionadas en el norte de Irán. ${ }^{16}$

La buena voluntad de Roosevelt de tener en cuenta las preocupaciones de la Unión Soviética por la seguridad de sus fronteras condujo a Stalin a pensar que el control de la Europa oriental era admisible a ojos de Estados Unidos, si se guardaban ciertas formas. ${ }^{17}$ Sin embargo, luego de Yalta hubo indicios de que después de la victoria Roosevelt

16 La bibliografía sobre estos temas es, naturalmente, enorme. Un balance historiográfico y un resumen de los problemas más importantes en Powaski, La Guerra Fría, sobre la política de contención de Churchill, en las pp. 77-79.

17 Powaski, La Guerra Fría, pp. 85-86. Powaski llega a afirmar que en este sentido, Roosevelt fue "cómplice” de Stalin en la ocupación soviética de Europa oriental (p. 86). Lo que lleva a preguntar si la Unión Soviética, víctima de una salvaje guerra de agresión no provocada, cuyo costo no tuvo parangón en la historia, debía detener a su victorioso ejército en sus fronteras sin aniquilar a sus enemigos, entre los que se contaban, como ya dijimos, varios de los estados limítrofes, cómplices y partícipes de la agresión alemana. $\mathrm{O}$ si, como vencedor con un costo terrible, permitiría la restauración de esos estados en la misma condición política hostil a ella anterior a 1939, como proponía Inglaterra para Polonia. Sólo una portentosa ingenuidad o mala fe argumental puede suponer algo semejante. Por otra parte, la demora en la apertura del "segundo frente" motivada en última instancia - más allá de pretextos plausibles - por la intención de desgastar el poder ruso tuvo el paradójico resultado de que los ejércitos soviéticos ocuparan la mitad de Europa y tomaran Berlín sin presencia de los otros aliados. 
aumentaría su "firmeza" frente a la URSS, preanunciando el cambio de política que llevaría a la ruptura de la Gran Alianza y a la Guerra Fría. ${ }^{18}$

Efectivamente, su sucesor, Harry S. Truman, consumó el trascendental viraje que en el lapso de poco más de un año y medio dejaría a Estados Unidos y la Unión Soviética como enemigos, encabezando dos bloques antagónicos en apenas contenida hostilidad, lo que marcaría el futuro mundial por décadas. Señalemos algunos hitos del proceso. El 9 de febrero de 1946, Stalin pronunció un discurso electoral ante importantes dirigentes del Partido Comunista y funcionarios del Estado soviético, en el que reapareció el clásico análisis leninista de la inevitabilidad de la guerra en la época del imperialismo, y destacó que el triunfo sobre los fascistas en el anterior conflicto había confirmado la viabilidad y fortaleza del sistema socialista, sin hacer ninguna mención del esfuerzo de los aliados. Deslizó elípticamente que la URSS podría contar con el arma nuclear en poco tiempo más y diseñó un plan de fortalecimiento de la economía y la sociedad soviéticas de cara a los nuevos desafíos, referido a la posibilidad de una creciente confrontación con las potencias capitalistas.

Menos de un mes después - el 5 de marzo de 1946, con la presencia del presidente Truman - Winston Churchill pronunció su célebre discurso en el Westminster College de Fulton, Missouri, en el que acuñó la representación - la "cortina de hierro" y sus variantes - que dominaría desde el campo occidental la retórica política, aludiendo a una tiranía comunista que se habría apoderado de Europa oriental.

18 Powaski, La Guerra Fría, p. 88. 
Lo más significativo en esa jornada de Fulton fue el apoyo que el exprimer ministro recibió con la presencia de Truman. Las líneas ideológicas generales de Occidente en la Guerra Fría fueron en gran parte concebidas y formuladas por Churchill, y encontraron su expresión en este decisivo discurso. Churchill asentó el poder frente a la Unión Soviética en el monopolio del arma atómica, compartido por Estados Unidos con Inglaterra y Canadá. Recordando su lucha contra el apaciguamiento con Hitler en la década de 1930, clamó por no cometer el mismo error con Stalin y diseñó una estrategia en la que la coalición de pueblos de habla inglesa debía actuar con firmeza en defensa de las tradiciones de libertad y derechos humanos frente a la imposición totalitaria, policial y tiránica que adjudicaba a la Rusia soviética. Aún reconocía que Rusia no quería la guerra y que eran legítimas sus preocupaciones por una frontera sin vecinos hostiles que favorecieran a Alemania, y recordaba la camaradería con Stalin durante el conflicto anterior, pero señalaba la necesidad de acentuar el predominio nuclear y la alianza militar occidental frente a sus supuestos intentos de continua expansión y hegemonía.

El 13 de marzo de 1946 Stalin contestó duramente a Churchill, afirmando que éste, al igual que Hitler, sostenía una teoría de superioridad racial, ahora anglosajona. Rusia había pagado un alto costo por la invasión alemana efectuada a través de Europa oriental y los objetivos perseguidos por la Unión Soviética allí eran pacíficos - aseguró el dirigente soviético-: sólo buscaba regímenes leales que garantizaran sus fronteras.

A partir de 1947 la confrontación fue adquiriendo un carácter irreversible. El 12 de marzo Truman pronunció 
un discurso ante el Congreso en el que diseñó nuevos objetivos y estrategias para la política exterior estadounidense, que luego se conoció como la "doctrina Truman". La base de esta política fue una visión maniquea de la situación mundial de posguerra, entendida como la confrontación entre dos "modos de vida": el "mundo libre" contra el "comunismo", según la fórmula utilizada a lo largo de la Guerra Fría. Al anunciar la ayuda militar y financiera a Grecia y Turquía, Truman diseñaba la estrategia que pasaría a llamarse de "contención” al comunismo, por la que Estados Unidos se haría presente con ayuda de alcances múltiples a cualquier gobierno que enfrentara un desafío comunista, del carácter que fuese. El objetivo primordial de Estados Unidos debía ser impedir la difusión del comunismo a las naciones no comunistas; es decir, "contener" el comunismo dentro de sus fronteras. ${ }^{19}$

La difícil situación europea, las amenazas de recesión que la debilidad de los mercados trasatlánticos implicaba para la economía estadounidense y los riesgos políticos de un avance del comunismo en un escenario de descontento y pobreza, motivaron la creación de un plan masivo de ayuda a la

19 Gaddis, Strategies; PowASKI, La Guerra Fría, pp. 95-96. Esta política de "contención" había sido esbozada el año anterior por George F. Kennan, encargado de negocios en la embajada de Estados Unidos en Moscú, en su famoso “telegrama largo". El telegrama, del 22 de febrero de 1946, en Churchill, Foreign, doc. 475, pp. 696-709. Fue publicado como artículo con agregados el año siguiente: $\mathrm{X}$, “The Sources of Soviet Conduct”, en Foreing Affairs, vol. 25, 4 (jul. 1947). El uso del seudónimo fue debido a que Kennan mantenía su condición de diplomático, pero era ampliamente conocido como autor del artículo. Véase Kennan, $A l$ final, pp. 33-42. El documento corregía la opinión del fallecido presidente Roosevelt y un sector de sus allegados en cuanto a que era posible manejar a Stalin en la posguerra con una política de buena voluntad y cooperación, lo que para Kennan era ingenuo. 
reconstrucción económica europea cuyos fundamentos fueron anunciados por el secretario de Estado general George Marshall en un discurso pronunciado en la Universidad de Harvard el 6 de junio de 1947. Como pura fórmula, la Unión Soviética fue incluida en la oferta de ayuda. Stalin tenía alguna expectativa inicial, pero la exigencia de someterse a controles externos y la imposición de integración en un mercado europeo hicieron que la invitación a la Unión Soviética y los países de Europa oriental y central bajo su influencia fuera rechazada. La Unión Soviética debió vetar la participación de Polonia y Checoslovaquia, que tenían mucho interés en el programa.

\section{LA KOMINFORM Y LA NUEVA CENTRALIZACIÓN DEL MOVIMIENTO COMUNISTA MUNDIAL}

La Guerra Fría provocó un endurecimiento interno en la URSS, abocada al enorme esfuerzo de reconstrucción de la posguerra. El régimen estalinista se retrajo a prácticas despóticas, y detrás de su monolitismo aparente y de los desmedidos alcances del "culto a la personalidad" incubaba enormes tensiones. ${ }^{20}$ La respuesta soviética a sus desafíos también condujo al reforzamiento del centralismo en el movimiento comunista internacional. Se canceló así la posibilidad de desarrollos nacionales autónomos de los partidos comunistas - orientación que se había enunciado en la resolución de disolución de la Internacional Comunista (IC) en 1943que recién serían retomados después de la muerte de Stalin

${ }^{20}$ Sobre el periodo, Deutscher, Stalin; Deutscher, Post Scritum; Medvedev, El Stalin. 
en Alemania Democrática, Polonia, Hungría y Checoslovaquia en procesos de gran intensidad e infortunados desenlaces, con el "policentrismo" enunciado por Togliatti y el Partido Comunista Italiano en 1956, y con las crecientes y abiertas diferencias del PC chino respecto de las orientaciones soviéticas a partir del XX Congreso del pcus ese mismo año. La Kominform fue el organismo que instrumentó hacia el movimiento comunista internacional el excesivo centralismo y el culto a Stalin. De su inicial papel de oficina coordinadora de información y enlace, pasó a ser un "tribunal, con poderes de excomunión”, como se evidenció en 1948 con la condena del "titismo" yugoeslavo, con atribuciones ampliadas a partir de 1949. Desde 1950 coordinó el Movimiento de la Paz, identificándose cada vez más con éste. ${ }^{21}$

La Oficina de Información de los Partidos Comunistas y Obreros (Kominform, tal es su acrónimo en ruso) fue creada el 5 de octubre de 1947 en una reunión reservada realizada en Szklarska Poreba (Polonia) con la presencia de los partidos comunistas de la Unión Soviética, Yugoslavia, Hungría, Polonia, Checoslovaquia, Bulgaria, Rumania, Italia y Francia. Oficialmente fue una organización consultiva sin capacidad para tomar decisiones vinculantes, aunque sirvió como mecanismo de transmisión de las orientaciones soviéticas a los partidos integrantes y a todo el movimiento comunista internacional, y de control de su aplicación. Tuvo una sede central, inicialmente en Belgrado, que en 1948, por la ruptura soviético-yugoeslava, se trasladó a Bucarest. La Kominform editó ;Por una paz duradera, por una democracia popular!, periódico publicado en ruso, inglés, francés y español, en el

${ }^{21}$ Marcou, El movimiento, p. 5. 
que eran frecuentes las grandes firmas del movimiento comunista mundial y que informaba sobre las actividades comunistas en todos los países del mundo, sometido previamente a la censura de Moscú. La Kominform también desplegó una intensa ofensiva propagandística tendiente a neutralizar toda influencia económica o política de Estados Unidos sobre Europa oriental; realizó reuniones con la presencia de los dirigentes más caracterizados del comunismo y elaboró resoluciones sobre las que se construyó, durante varios años, la táctica de la mayoría de los partidos comunistas del mundo. ${ }^{22}$ Es por esto que fue calificada como "guía" de las orientaciones del movimiento comunista internacional y también como su portavoz ortodoxo y autorizado en el escenario internacional. ${ }^{23} \mathrm{La}$ integración de la Kominform respondió a la especificidad europea del escenario inicial de la nueva confrontación, con la presencia de los partidos comunistas de los países de Europa central y oriental (con dos ausencias notables: el partido comunista alemán y el albanés) y de los partidos comunistas de Italia y Francia, los más fuertes y con mayor autoridad política y moral en Occidente. ${ }^{24}$

La creación del Kominform fue el inicio, bajo el signo de la Guerra Fría, de otra etapa del movimiento comunista. Las directivas emanadas de su reunión constitutiva señalaron el fin del periodo de indefinición del régimen político de los países del este de Europa, con la rápida asunción del control total del poder por los partidos comunistas bajo la forma de "democracias populares", y con indicaciones de

${ }^{22}$ Sobre la Kominform: Marcou, La Kominform; Marcou, El movimiento.

${ }^{23}$ Marcou, El movimiento, pp. 6, 7.

${ }^{24}$ Marcou, El movimiento, p. 8. 
endurecimiento de la línea política a partir de la crítica de los comunistas yugoeslavos, la estrella del momento, a los partidos comunistas de Italia y Francia por no haber podido o sabido realizar la revolución en el proceso de la liberación del enemigo nazifascista y por haber sido excluidos en mayo de 1947 de sus respectivos gobiernos de coalición de la inmediata posguerra sin presentar resistencia alguna.

El informe central estuvo a cargo de Andréi Zhdánov y documenta las percepciones y posiciones de la URSS en la nueva coyuntura internacional. ${ }^{25}$ Como bien señaló Fernando Claudín: "hay pocos documentos en la historia del movimiento comunista que reflejen tan transparentemente

${ }^{25}$ Andréi Zhdánov (1896-1948) era una voz autorizada del Pcus. Bolchevique desde 1915, participó en la Revolución y en 1922 se vinculó políticamente a Stalin. En 1927 integró el Comité Central del Partido y en la década de 1930 trabajó activamente en la industrialización de la URSS. Se destacó cada vez más en el grupo cercano a Stalin, y se convirtió en el vocero del "realismo socialista" en arte y literatura. En 1934 sucedió al asesinado Kirov en la secretaría del pcus en Leningrado (San Petersburgo) y dirigió la dura represión que siguió al atentado. En 1940 se encargó de la incorporación de Estonia a la URSS y durante la segunda guerra mundial participó como responsable político máximo de la mítica resistencia de Leningrado al cerco alemán de la ciudad. Encabezó en 1944 la Comisión Aliada para Finlandia. Después de la guerra insistió en su línea del realismo en cuestiones de arte y fue responsable del hostigamiento y la persecución de notables figuras, como la poeta Ajmátova y los compositores Shostakovich y Prokofiev. En 1947 apareció como la principal figura de la Kominform. Su poder político se diluyó por su severo alcoholismo y su nombre se reactualizó póstumamente cuando apareció como una de las supuestas víctimas del fraguado "complot de los doctores”, poco antes de la muerte de Stalin. El informe de 1947 fue publicado por el Partido Comunista Mexicano, junto con la declaración y resolución constitutivas de la Kominform: ZDHÁnov, Sobre la situación. 
la subordinación de la lucha revolucionaria mundial a las exigencias de la política exterior soviética". ${ }^{26}$

El punto de partida fue la evaluación de la nueva correlación de fuerzas entre socialismo y capitalismo surgida de la guerra mundial, presentada como un "cambio radical" en favor del primero por la victoria y fortalecimiento de la Unión Soviética, que acrecentó su importancia y autoridad, la amplitud de la simpatías mundiales recogidas por su esfuerzo en la contienda y su esencial y enorme contribución a la destrucción del fascismo, que derivó en la separación del sistema imperialista de varios países de Europa central y sudoriental: Polonia, Checoslovaquia, Rumania, Hungría, Yugoslavia, Bulgaria y Albania. Entre las potencias capitalistas el rasgo fundamental fue el fortalecimiento militar y económico de Estados Unidos, en contraste con la destrucción de las tres potencias fascistas - Alemania, Italia y Japón-, el extremo decaimiento de Francia y la debilidad de Inglaterra en su zona de influencia - el Oriente árabe, Asia sudoriental, los dominios del Imperio británico y América del Surfrente a la creciente competencia estadounidense.

Zhdánov, en lo que fue el punto central del documento, manifestó que el mundo se encontraba ahora dividido en dos campos: el "imperialista", dirigido por Estados Unidos, y el de las "fuerzas pacifistas", por la Unión Soviética. La política estadounidense estaba dirigida agresivamente contra "los países de la nueva democracia, contra el movimiento proletario de todas las naciones y contra las fuerzas defensoras de la libertad antiimperialista de todos los países”. Concluyó, por tanto, que debían intensificarse los lazos de unión y de

${ }^{26}$ Claudín, La crisis, p. 428. 
recíproca información entre los partidos miembros, para lo cual era indispensable crear la Oficina de Información, que pudiera promover "el intercambio de experiencias y, en caso necesario, coordinar las actividades de los partidos comunistas sobre la base de una información mutua".

En junio de 1948, la Kominform se reunió en Bucarest con un único objetivo: luego de la ruptura entre Stalin y Tito, efectuar una condena brutal contra el régimen comunista yugoslavo, que sería obedientemente aceptada por todos los partidos comunistas. A partir de este acontecimiento, se exacerbó el culto a la URSS, al ejército soviético y a Stalin, "tríptico en torno al cual se organizará la propaganda de la lucha por la paz". ${ }^{27}$

La tercer gran reunión de la Kominform, y la última pública, se realizó en Hungría, en un sanatorio de los montes Matra, en noviembre de 1949. El primer informe fue presentado por Mijail Suslov, nuevo ideólogo del Pcus, ${ }^{28}$ y se tituló, sin mayor originalidad, La defensa de la paz y la lucha contra los instigadores de la guerra, y se erigió en el material doctrinal básico del Movimiento Internacional por la Paz. El

27 Marcou, La Kominform, pp. 130-131.

28 Mijail Suslov (1902-1982). Se afilió al bolchevismo en 1921, trabajando con campesinos pobres. Entró al aparato estatal y en la policía política en 1931. Participó activamente en las purgas de los años treinta y en la deportación de los chechenos durante la segunda guerra. Stalin lo llevó a trabajar en el aparato central del Partido. Ingresó en el Comité Central en 1941. Trabajó en la represión de los colaboracionistas en Lituania después de la guerra. Entró al secretariado del pcus en 1947 y al Politburó (Presidium en la época) en 1952. Reemplazó a Zdhánov en el trabajo ideológico. Continuó como la eminencia gris del pcus hasta su muerte. Medvedev sostiene que Stalin lo había elegido como su sucesor, y su muerte interrumpió el proceso, véase Medvedev, El Stalin. 
sucesor de Zdhánov retomó su esquema del mundo dividido en dos campos, acentuado desde 1947, así como el cambio de la correlación de fuerzas favorable al campo del socialismo, la democracia y la paz. La economía capitalista estaba acosada por una crisis general, que se iba agravando continuamente. Los imperialistas habían desatado en el mundo una auténtica psicosis de guerra, una "cruzada" anticomunista, leyes antiobreras y antisindicales y la creación de regímenes reaccionarios - Alemania Occidental y la Yugoslavia de Tito-, y la respuesta a todo ello es el Movimiento por la Paz, que se asienta también en la voluntad de sostener la coexistencia pacífica entre distintos regímenes sociales, teoría cuya autoría se otorgó a Stalin en 1931. La política comunista se definía, entonces, a partir de esta confrontación a escala mundial:

La clase obrera, los partidos comunistas y obreros, tienen como misión ponerse a la cabeza de la lucha todas las organizaciones sociales de masas para defender la paz; tienen como misión orientarlas y darles un carácter activo [...] a escala local, nacional e internacional. ${ }^{29}$

La Kominform, como tarea principal, deberá organizar la propaganda de todo el movimiento para salvaguardar la paz.

El informe de Palmiro Togliatti, ${ }^{30}$ La unidad de la clase obrera y las misiones de los partidos comunistas y obreros,

${ }^{29}$ Marcou, La Kominform, pp. 133, 136, la cita de Suslov en p. 135. Una aguda crítica de izquierda al informe Suslov en Claudín, La crisis, pp. 531-534.

30 Palmiro Togliatti (1893-1964). Compañero de Gramsci y principal dirigente histórico del Partido Comunista Italiano en la lucha contra el 
estuvo dedicado a la crítica por el papel jugado por la socialdemocracia en "la salvación provisional del capitalismo y el imperialismo”, por el odio a la URSS de los socialdemócratas de derecha y a explicar los procesos de fusión de los partidos comunistas con los elementos socialistas de "izquierda" en las democracias populares. Togliatti planteó una unidad "por la base” de la clase obrera, de los comunistas con los obreros socialdemócratas y católicos, y la necesidad de reafirmar la unidad sindical. El último informe del dirigente rumano Gheorghiu-Dej, ${ }^{31}$ El Partido Comunista yugoslavo, en poder de asesinos y espias, denunció el camino adoptado en Belgrado como el del "nacionalismo burgués, el fascismo y la traición directa” y fue el justificativo ideológico de las purgas y persecuciones de esos años en las democracias populares.

\section{DIONISIO ENCINA, UN DIRIGENTE ESTALINISTA}

El principal responsable de la política del PCM en el periodo que aquí abordamos fue su secretario general, Dionisio Encina Rodríguez, cuya biografía política sintetiza una dura experiencia de compromiso, lucha social y represión, junto con la férrea disciplina y obediencia a la "línea” general del comunismo orientada desde Moscú y sus mediaciones por

\footnotetext{
fascismo y en la fundación y consolidación de la República italiana. Una de las figuras más relevantes del movimiento comunista internacional y de la historia política del siglo pasado.

31 Gheorghe Gheorghiu-Dej (1901-1965). Sindicalista, prisionero en campo de concentración del régimen fascista de Antonescu, dirigente de la resistencia, secretario general del Partido Comunista Rumano en 1944-1965, primer ministro de Rumania de 1952 a 1955 y presidente de la República de 1961 a 1965.
} 
medio de indicaciones específicas recibidas de emisarios del aparato internacional comunista - dirigentes como Codovilla y Browder, por ejemplo, o apparátchiki menos connotados de la jerarquía comunista - , de organismos como la Kominform en sus resoluciones y periódico, de servicios de la embajada soviética o transmitidas en reuniones internacionales de los partidos en una dinámica todavía no bien conocida para esta época en sus detalles operativos. ${ }^{32}$ Encina, además, formó parte de la red de incondicionales del poder soviético, y su permanencia en la dirección del PCM se explica precisamente por su pertenencia al aparato comunista y su condición de "hombre de confianza" de Moscú; es un buen ejemplo de la generación de dirigentes comunistas latinoamericanos de la época del estalinismo maduro, posterior a las “purgas” de la década de 1930, cuya piedra angular política fue la admiración irrestricta e incondicionalidad en la adhesión a la "patria del socialismo" y sus dirigentes, consolidada en el transcurso de la segunda guerra mundial.

La mayoría de estos dirigentes, y Encina no fue ciertamente la excepción, estuvo hondamente influida por la

32 Se conoce bastante mejor la dinámica del aparato comunista en América Latina de la primera década de la Komintern. Después de 1930, ya asentada la dirección del grupo estalinista en la Internacional, ese funcionamiento todavía no ha sido estudiado en profundidad, y menos aún después de su disolución en 1943. Se piensa en una mayor autonomía y libertad de movimientos respecto de Moscú de los partidos comunistas latinoamericanos a partir de la segunda guerra mundial y hasta finales de la década de 1940, pero creo que esta hipótesis revela más un desconocimiento que una realidad. El secretismo del aparato es un obstáculo difícil de resolver para los historiadores, a pesar de la apertura de algunos de los archivos en Moscú, en particular los correspondientes al periodo de la Komintern (1919-1943). No hay obviamente acceso a los de los servicios secretos o especiales del pcus y del Estado soviético. 
concepción de Earl Browder ${ }^{33}$ secretario general del Partido Comunista de Estados Unidos, acerca de la necesidad de la colaboración de clases entre el proletariado y la burguesía "progresista" en todo el periodo histórico de la revolución democrática-burguesa, subordinando el primero a la segunda. Ese influjo profundo no cesó a pesar de la crítica a Browder efectuada en 1945 - centralmente dirigida a su idea de una colaboración de largo plazo entre las dos grandes potencias vencedoras de la segunda guerra, Estados Unidos y la URSS - ya que se articulaba con una concepción muy asumida del proceso revolucionario por "etapas", cristalizado en buena medida desde la concepción del frente popular antifascista elaborado en el VII Congreso de la IC en $1935 .{ }^{34}$ La lucha antiimperialista, posible de ser compartida con un importante núcleo de la burguesía llamada "nacional”, era la posibilidad articuladora esencial de esta colaboración de clases, y su radicalismo podía ocultar por un tiempo la defección comunista de la postulación de la hegemonía del proletariado en esa lucha e, incluso, en todo el proceso de

33 Earl Browder (1891-1973). Pacifista durante la primera guerra mundial, fue encarcelado. Se afilió al Partido Comunista (PCUSA) en 1921. Viajó a Moscú y trabajó para la Comintern en China en la década de los veinte. Secretario del pCusa en 1930. Apoyó a Roosevelt y el New Deal. En 1940 fue enviado de nuevo a prisión. Después de un periodo de auge con sus teorías, que recibieron el apelativo de browderismo, y de su influencia sobre todo el comunismo de América Latina, fue criticado por Jacques Duclos, comunista francés, en Cabiers du Communisme en abril de 1945, y destituido de la dirección del Pcusa, que él había convertido en una "asociación" política. Expulsado del PCusA en 1946, fue perseguido por el macartismo. Véase Ryan, Earl Browder.

${ }^{34}$ Carr ha señalado la importancia de estudiar en profundidad el fenómeno del browderismo y su influencia en México, y deberíamos agregar que en el comunismo de toda América Latina. Véase Carr, "Hacia", p. 578. 
transformación social revolucionaria. Esta concepción resulta clave para entender las relaciones del PCM con los gobiernos de Cárdenas, Ávila Camacho e, incluso, Miguel Alemán, hasta la crítica y ruptura con su régimen en 1949.

Como dijimos, la carrera política de Encina muestra dos facetas: el aguerrido militante del movimiento obrero y el burócrata del aparato de dirección comunista. ${ }^{35}$ Nació en La Blanca, Zacatecas, el 9 de octubre de 1907, aunque otros señalan a Torreón como su lugar natal. Se inició como obrero metalúrgico, lo que le confería la condición proletaria tan apreciada en la cultura comunista. Activista probado en las luchas populares, en la organización sindical y en el rigor represivo, esto último también muy apreciado en el contexto partidario, poco a poco se tornó en un avezado conocedor de la difícil maraña de la cultura organizacional del Partido Comunista de México. Comenzó a militar en el movimiento sindical en 1927, viajó a Centroamérica el año siguiente con Julio Antonio Mella, Rafael Carrillo, Jorge Fernández Anaya ${ }^{36}$ y otros militantes para realizar tareas de la Liga

${ }^{35}$ La biografía política de Encina ha sido reconstruida sobre la base de tres fuentes: Fernández [ANAYA], “45 años”, un artículo apologético escrito en su 45 cumpleaños por un destacado miembro de la dirección del PCM y "compañero de lucha", tal como era usual en el protocolo estalinista; Jeifets, Jeifets y Huber, La Internacional, p. 101; De Pablo Hammeren, "Encina”. En esta última fuente se menciona Torreón, Coahuila, como lugar de nacimiento de Encina.

${ }^{36}$ Jorge Fernández Anaya, de origen indígena, fue un importante dirigente de la Juventud Comunista y del Partido Comunista de México (varias veces miembro de su Comité Central), de la Internacional Comunista en el Buró del Caribe, militó también en la Liga Antiimperialista de las Américas y en el Socorro Rojo Internacional. Participó en el Comité Manos Afuera de Nicaragua en 1928 y en la formación del Partido Comunista de El Salvador, como organizador de los campesinos en 
Antiimperialista de las Américas y el Socorro Rojo Internacional, y en 1929 ingresó a la Juventud Comunista integrando su Comité Central, y también al Partido Comunista de México. En ese momento, los comunistas eran acosados por una fuerte represión desatada tras la rebelión escobarista. Encargado de la dirección del comité estatal comunista de Coahuila, realizó numerosas acciones de propaganda y mítines contra el régimen callista; el $1^{\circ}$ de noviembre de 1930 fue secuestrado por la policía acusado de "preparar la insurrección”, torturado en Torreón y trasladado detenido e incomunicado al Distrito Federal, quedando liberado 15 días después por la movilización del partido; en 1934 resultó herido durante la represión de un mitin electoral comunista también en Torreón. El año siguiente reunió sindicatos para organizar la Federación Sindical Revolucionaria de Coahuila y consiguió su adhesión a la Confederación Sindical Unitaria de México. El 22 de septiembre de 1935 estuvo entre los fundadores del Comité de Defensa Proletaria de La Laguna, siendo su secretario general, y en el ascenso de la lucha social organizó y dirigió en 1935-1936 - junto con Jorge Fernández Anaya, miembro del Comité Central comunista, y Mario Pavón Flores - ${ }^{37}$ el fuerte movimiento de 25000

1930. En 1948 fue director ejecutivo de La Voz de México y miembro del Consejo Editorial de la revista Teoría, ambos del PCM. Fernández AnAYA, “La fundación”; su biografía política en JeIFETs, JeIFETS y Huber, La Internacional, pp. 106-107.

${ }^{37}$ Mario Pavón Flores fue el más destacado abogado laboral y asesor sindical mexicano en las décadas de los treinta, cuarenta y cincuenta. Asesoró la huelga de los petroleros de 1934 a 1936, del Sindicato Mexicano de Electricistas de 1936, de los jornaleros de La Laguna el mismo año, de los telefonistas de 1943 y 1944, al sindicato de tranviarios entre 1941 y 1953 , de mineros metalúrgicos entre 1935 y 1946, de los técnicos y manuales de 
jornaleros agrícolas de la región lagunera, en el que Encina gozó de gran prestigio, que culminó con la huelga general de peones agrícolas de 1936, el cual precipitó el reparto de tierras en la Comarca, uno de los más significativos y radicales del gobierno cardenista.

Encina asistió como delegado al Congreso constitutivo de la СтM, se destacó en el proceso de unificación de los trabajadores de Coahuila y fue electo, por su prestigio entre los obreros, como secretario de Trabajo y Conflictos de la Federación de Trabajadores del Estado de Coahuila-CTM. Cuando la derecha sindical intentó expulsarlo de la Federación Única de Trabajadores de la Comarca Lagunera, todas las organizaciones obreras y campesinas lo respaldaron y se frustró la maniobra. En 1936 fue electo secretario del PCM para Coahuila y secretario de conflictos obreros de la Federación Sindical afiliada a la CTM.

Llegamos al momento bisagra de la trayectoria de Dionisio Encina. En el Pleno del Comité Central de septiembre de 1939, en el que se enjuició a la dirección de Hernán Laborde y Valentín Campa, presidió los debates. Seleccionado por Vittorio Codovilla, el enviado de la Internacional, en diciembre de ese año formó parte de la "Comisión depuradora" de los disidentes, encabezada por Andrés García Salgado, quien sería luego su secretario de organización. ${ }^{38}$ Como ya vimos, en

cine entre 1942 y 1954 . Fue consejero de los obreros ferrocarrileros en el gran movimiento huelguístico de 1959, sostuvo relaciones de camaradería y gran confianza con Demetrio Vallejo y Valentín Campa. Militó en el Partido Comunista entre 1936 y 1941, en 1947 la стм de Fidel Velázquez lo atacó virulentamente por comunista, "depurándolo" de sus filas. Véase Alzaga, "Mario Pavón Flores".

38 Andrés García Salgado (1911, 1913?-1985). Siendo estudiante de la 
el Congreso Extraordinario de marzo de 1940 fue nombrado secretario general del PCM, en sustitución del recién expulsado Hernán Laborde. Su designación fue muy resistida:

El trabajo de grupos y fracciones siguió existiendo en el seno del Partido inmediatamente después de la realización del Congreso Extraordinario. El Congreso Extraordinario no eligió una dirección nacional cohesionada y unida. Un número determinado de camaradas, incluyendo entre ellos a cuadros de dirección nacional, no estuvieron convencidos nunca de una serie de acuerdos del Congreso de 1940; por ejemplo, en la actitud hacia Vicente Lombardo Toledano, en la expulsión de Laborde y Campa, en la elección del Secretario General del Partido. Algunos cuadros de dirección superior no consideraron a la dirección electa en el Congreso Extraordinario, y en particular al Secretario General del Partido, como los más capaces, los más representativos, los que mejor podrian garantizar el desarrollo del Partido y la aplicación de su politica. ${ }^{39}$

Además de la presencia decisiva de Codovilla para su carrera en el aparato comunista, en ese periodo Encina se vinculó

Preparatoria Nacional y militante de la Juventud Comunista, se trasladó en 1927 a Nicaragua para luchar con Sandino. Regresó a México en 1929 con él. En marzo de 1930 se separó de Sandino y volvió a la Ciudad de México. El primero de mayo de 1933 fue detenido. Ese año viajó a Cuba, junto con Marinello y Dorantes, a trasladar las cenizas de Mella. En 1936 participó en las Brigadas Internacionales de la Guerra Civil Española. En el Congreso Extraordinario de 1940 formó parte de la "comisión depuradora" que expulsó a Laborde y Campa, siendo nombrado presidente de la Comisión de Control del Partido. Fue expulsado en 1943. A partir de entonces se integró al sindicalismo oficial. JeIFETs, JeIFets y Huber, La Internacional, p. 122; De Pablo Hammeken, La Rojería.

${ }^{39}$ Comité, La lucha, p. 28. Las cursivas son mías, H.C. 
estrechamente y fue aconsejado por Earl Browder y el cubano Blas Roca, uno de los exponentes claves de la línea browderista en América Latina. ${ }^{40}$

Veamos, en datos apretados, su paso por la dirección del PCM. El 27 de abril de 1943 fue detenido en Torreón, pero liberado rápidamente. Más tarde, ese mismo año, dirigió las expulsiones de Miguel Ángel Velasco y la célula "José Carlos Mariátegui”. En 1944 y 1945 impulsó de nuevo, junto con su secretario de organización Blas Manrique, ${ }^{41}$ la orientación browderista en el PCM, postulando la "unidad nacional" y la suspensión de cualquier confrontación social o política hasta lograr la victoria sobre el nazifascismo, y en enero de 1946 viajó a Cuba para participar en la III Asamblea Nacional del Partido Socialista Popular cubano dirigido por su amigo Blas Roca. Ese mismo año condujo al partido a apoyar la candidatura presidencial de Miguel Alemán y fue precandidato a senador por el oficialista PRM en Coahuila. En enero de 1947 representó al PCM en los debates de la Mesa Redonda de los Marxistas Mexicanos convocada por Lombardo Toledano. En 1948 dirigió la expulsión del grupo de Sánchez Cárdenas,

${ }^{40}$ Blas Roca Calderío (1908-1987). Vendedor de periódicos, carpintero y maestro. Ingresó al Partido Comunista de Cuba (PCC) en 1929, al Comité Central en 1931 y al Buró Político en 1933. Secretario general del PCC de 1934 a 1936. Desde 1944 dirigió el Partido Socialista Popular, nuevo nombre del pcc, bajo influencia browderista. JeIFETs, JeIfETS y Huber, La Internacional, pp. 284-286.

${ }^{41}$ Blas Manrique Arrevillaga (1913-2005). Desde 1943 ocupó el cargo de secretario de organización del PCM. En enero de 1947 representó al PCM en la Mesa Redonda de los Marxistas Mexicanos. A principios de mayo fue secuestrado por la policía en la Ciudad de México. En 1949 fue excluido del Comité Central, pues su esposa, Miriam Minsky, fue acusada de ser agente del FBi. Se trasladó a Tijuana, donde siguió militando en el PCM y fundó una librería de izquierda. De Pablo Hammeken, "Manríque". 
y al año siguiente participó en el Congreso Mundial de Partidarios de la Paz, en París. Fue arrestado el $1^{\circ}$ de mayo de 1952 y de nuevo en 1954. En 1952 fue candidato a senador en Cohauila por el PCM. En febrero de 1956 estuvo presente en Moscú, representando al PCM, en el XX Congreso del PCUs. En febrero de 1959 viajó a la URSS para pedir el apoyo de los soviéticos contra la tendencia disidente de Arnoldo Martínez Verdugo, sin éxito; ya palidecía su buena estrella en Moscú. Llegó el derrumbe: a su regreso de la URSS, el 2 de septiembre fue arrestado, en el contexto de la represión al movimiento ferrocarrilero, y, estando en prisión, el XIII Congreso del PCM realizado en mayo de 1960 lo retiró de la secretaría general sustituyéndolo por un secretariado colectivo encabezado por su oponente, Martínez Verdugo. En el XIV Congreso del partido, reunido en 1963, fue excluido de todos los órganos dirigentes. En 1965 fue transferido a la cárcel de Santa Marta Acatitla y, ese mismo año, puesto en libertad. De todos modos no volvió ya a la dirección del partido. En el XIX Congreso del PCM, celebrado en 1981, recibió un homenaje. Murió el 21 de agosto de 1982.

La prolongada jefatura de Encina en el comunismo mexicano no fue afortunada. Carecía de las dotes necesarias para enfrentar situaciones complejas y desfavorables como las que se presentaron desde el final de la guerra. Su actuación como "depurador" del partido a lo largo de la década de 1940 se convirtió en un obstáculo para la reincorporación de valiosos dirigentes, como Campa y Laborde, de quienes recelaba y a quienes temía. Una caracterización impiadosa pero acertada lo muestra como "inepto, inseguro e incompetente"; desconfiado de todos los que mostrasen capacidades de liderazgo, apartaba de puestos de responsabilidad a quienes 
suponía posibles competidores y, en lo posible, los "purgaba” sin escrúpulos. Se rodeó de una camarilla de incondicionales y sólo se apoyaba en su talentosa esposa, Paula Medrano, y en su "mano derecha”, José Encarnación Chon Pérez Gaytán, quien lo abandonó en la confrontación interna de 1957 pasándose a los disidentes. ${ }^{42}$ Estrecho de miras, dogmático, no se entendía con los intelectuales y se mostraba servil con los dirigentes soviéticos; era mal orador e incapaz como organizador y propagandista.

\section{LA LUCHA POR LA PAZ COMO EJE POLÍTICO DEL PCM}

\section{El $X$ Congreso}

El X Congreso del Partido Comunista Mexicano se realizó entre el 24 de noviembre y el 1ํo de diciembre de 1947, transcurridos apenas dos meses desde la conformación de la Kominform. De esta manera el partido tomó la delantera

42 José Encarnación Chon Pérez Gaytán (1922-2006). Ingresó al PCM en 1939. En febrero de 1948 presentó, junto con Lumbreras, la defensa de Sánchez Cárdenas, Aroche y Martínez Camberos. A diferencia de ellos, no fue expulsado. Ese año se integró a la dirección del PCM. En 1952 fue candidato a diputado por Nuevo León. En febrero de 1956 estuvo en Moscú en el XX Congreso del pcus por el PCM. En 1957, siendo miembro de la Comisión Política, integró con Martínez Verdugo, Terrazas y Unzueta la oposición renovadora contra Encina. En 1958 participó en el movimiento ferrocarrilero y en 1959 fue arrestado en Monterrey, en el contexto de la represión de ese movimiento, y enviado a Lecumberri. Estando preso, el XIII Congreso del PCM, celebrado en 1960, lo eligió como parte de un secretariado colectivo que sustituyó a Encina y que existió hasta 1963. Dentro de la cárcel dirigió a los presos comunistas y colaboró estrechamente con Campa. En 1964 fue puesto en libertad. En 1965 fue detenido una vez más, durante un allanamiento del local del PCM. En marzo de 1968, siendo tercer secretario del Comité Central del PCM, fue aprehendido nuevamente. En 1979 fue electo diputado federal por el PCM. 
en la formulación y aplicación de la nueva línea política surgida en la reunión de los partidos comunistas europeos. El informe central fue presentado por Dionisio Encina, ${ }^{43}$ quien subrayó que el Congreso se reunía en momentos en que las posibilidades de una paz firme y duradera, y el cumplimiento de los compromisos y programa de la guerra pasada estaban siendo "duramente obstaculizadas por el imperialismo mundial, particularmente el yanqui”. Glosó el reciente informe de Zdhánov para explicar la situación internacional, señalando como sus puntos fundamentales el cambio en la correlación mundial de fuerzas, el debilitamiento del orden social capitalista y el fortalecimiento de Estados Unidos, que ahora pretendía extender su dominio y afirmar su supremacía económica mundial. El sistema colonial se encontraba en crisis, y se asistía a una intensificación de las luchas de los pueblos oprimidos y dependientes contra el imperialismo. Habían surgido las democracias populares y la Unión Soviética - "baluarte de la paz" estima Encinas-, que resistía con su política de paz los planes de agresión imperialista y postulaba la eliminación de las armas de destrucción masiva enfrentando el chantaje nuclear, encabezaba las luchas contra una nueva guerra, y el sometimiento de los pueblos mediante los planes de Truman, Marshall y Clayton. ${ }^{44}$

43 Encina, $X$ Congreso. Se reproduce en Concheiro y Payán, vol. I, pp. 464-523. Citamos por esta edición.

${ }_{44}$ William L. Clayton (1880-1966), gran empresario algodonero de Texas, como asistente del secretario de Estado para Asuntos Económicos en 1944 promovió el libre comercio y la cooperación internacional asociada a él. Fue asesor económico de Truman en Potsdam y el primer subsecretario de Estado para Asuntos Económicos en 1946 y 1947; desde esta función cumplió un papel importante en la organización de la reconstrucción europea y el Plan Marshall. 
Encina anunció una posible y cercana crisis económica del capitalismo, azotada nuevamente por la sobreproducción relativa, a cuya contención estaba dirigido el Plan Marshall, en la estrategia de Estados Unidos de monopolizar mercados e incrementar sus exportaciones para "arrojar de esa manera el peso de la crisis sobre las espaldas de las naciones". ${ }^{45} \mathrm{Un}$ claro designio de Washington era reconstruir Alemania Occidental y Japón como instrumentos de su hegemonía mundial; la campaña mundial anticomunista significaba también otra herramienta de dominio, al intentar destruir a las únicas fuerzas capaces de llevar hasta el final la lucha por la soberanía y la independencia nacional: los partidos comunistas. Encina realizó un recorrido por situaciones particulares señalando el triunfo de la república democrática en Italia como resultado de la acción y la fuerza del Partido Comunista Italiano contra las maquinaciones monárquicas de las fuerzas de ocupación angloyanquis y los reaccionarios y profascistas, la lucha en Francia del Partido Comunista que enfrentó resueltamente al gaullismo y al entreguismo, y la traición de los socialistas de Blum y Ramadier, que impulsaron la salida de los ministros comunistas del gabinete. Destacó los éxitos de la lucha del pueblo chino dirigido por el partido comunista contra la "camarilla feudal-fascista" del Kuomintang y la ayuda militar recibida desde Estados Unidos. Mencionó las luchas de los pueblos de la India, Egipto y los pueblos árabes por su plena independencia, al igual que la guerrilla griega a pesar del apoyo otorgado por Truman a la monarquía fascista y a los traidores nacionales. Denunció con fuerza el sostén abierto que Estados Unidos e Inglaterra brindaban

45 Encina, X Congreso, en Concheiro y Payán, p. 476. 
al régimen fascista de Franco resistiendo la intervención de Naciones Unidas, incrementando el intercambio comercial y brindándole elementos bélicos. Denunció la política inglesa de un régimen franquista sin Franco, de la que eran cómplices "Prieto y sus amigos monárquicos". ${ }^{46}$ Llamó a la solidaridad con la lucha del pueblo español, con su movimiento guerrillero y sus manifestaciones y huelgas políticas, al "crecimiento de un más efectivo y poderoso movimiento de solidaridad política y material con el pueblo español, contra el franquismo y su sangriento terror" ${ }^{47}$

La intervención de Encina abordó el panorama político de América Latina a partir de definir que la región sufría una despiadada agresión por parte de Estados Unidos, dirigida a atacar a las "débiles industrias nacionales" a través del libre comercio impulsado por el subsecretario Clayton; en nombre de la defensa continental Estados Unidos impuso su Pacto Militar ${ }^{48}$ como parte del "plan de preparación de una nueva guerra mundial y las intenciones de arrastrar a todos los países latinoamericanos al carro de agresión y provocación internacional contra la URSS y los países democráticos, como carne de cañón". La política anticomunista se impulsó por medio de la "traición" de algunos círculos

46 Encina, X Congreso, en Concheiro y Payán, p. 481.

47 Encina, $X$ Congreso, en Concheiro y Payán, p. 482.

${ }^{48}$ Encina se refiere al Tratado Interamericano de Asistencia Recíproca (TIAR), también llamado Tratado de Río, pacto de defensa mutua interamericano de duración indefinida firmado el 2 de septiembre de 1947 en Río de Janeiro, con la participación de Estados Unidos y 18 países de América Latina y el Caribe, a los que se sumaron Nicaragua en 1948 y Ecuador en 1949. En el plano político esta alianza se expresó en la Organización de Estados Americanos, constituida en abril de 1948 en la IX Reunión Interamericana celebrada en Bogotá. 
gubernamentales y de la burguesía que servía a intereses antinacionales no solamente en el plano político sino en el económico, y lo mostró en tres casos paradigmáticos: Chile, Brasil y Cuba. El "paso al campo del imperialismo" de Gabriel González Videla en Chile, que expulsó a los ministros comunistas del gabinete, ilegalizó al Partido Comunista, rompió relaciones con la URSS, Yugoeslavia y Checoslovaquia, reprimió al movimiento obrero y desató una gran campaña de persecución a los comunistas, quienes fueron un elemento clave en la organización e impulso del Frente Popular que lo llevó al poder. En Brasil la lucha de las fuerzas populares y democráticas lograron importantes éxitos en la organización y unificación obrera, la convocatoria a la Constituyente y el empuje de la revolución democrática burguesa. Sin embargo, el régimen del mariscal Dutra, francamente alineado con Estados Unidos, ilegalizó al partido comunista y al movimiento sindical y rompió relaciones con la URSS. En Cuba, el gobierno del presidente Grau había cedido a las fuerzas clerical fascistas y al imperialismo yanqui, adoptando posiciones reaccionarias y facilitando maniobras divisionistas en la Confederación de Trabajadores de Cuba dirigida por el comunista Lázaro Peña. La retórica combativa de Encina no logró ocultar las graves derrotas que sufrió la política de los partidos comunistas de apoyo o confianza en los sectores burgueses "progresistas" de esos países, que pueden leerse entre líneas.

Pleno del Comité Central de octubre de 1949

Dos años más tarde, en el Pleno del Comité Central realizado en octubre de 1949, se abordó de nuevo el escenario 
internacional. ${ }^{49}$ Podemos detectar una incoherencia de tiempos en el documento de esta reunión, que es buena muestra de las prácticas de obediencia reverencial hacia el poder de Moscú mostrado por el encinismo. En la versión impresa de que disponemos, de 1950, la intervención que el secretario general del PCM supuestamente efectuó en la reunión repite textualmente muchos argumentos y pasajes del informe de Suslov en Hungría, presentado dos semanas después de la realización del Pleno e impreso un mes después. ${ }^{50} \mathrm{Sal}-$ vo suponer en él dotes anticipatorias, lo que obviamente nada autoriza, seguramente Encina "retocó y aggiornó" para la impresión el material que había presentado al Comité Central - que ya no conoceremos - al enterarse de la nueva "guía" de la Kominform, para sintonizar completamente con ella. El informe del secretario general del PCM, en su renovada versión, planteó que el rasgo dominante de la situación era el incremento de la preparación de Estados Unidos para desatar una guerra de agresión contra la Unión Soviética. Reafirmaba lo sostenido dos años antes por Zdhánov, y subrayado dos semanas después por Suslov en la Kominform, acerca del cambio en la correlación de fuerzas favorable al campo socialista, asentado en la sólida reconstrucción de la URSS, la consolidación de las democracias populares y dos hechos recientes muy ponderados (también por Suslov): la "grandiosa victoria" de los revolucionarios chinos con la instauración de la República Popular China ${ }^{51}$

\footnotetext{
${ }^{49}$ Encina y Valdés, Por la Paz.

${ }^{50} \mathrm{El}$ informe de Suslov, junto con los otros, fue publicado en ;Por una paz duradera, por una democracia popular!, el 2 de diciembre de 1949.

${ }^{51}$ Mao Tse-tung proclamó la República Popular China el 1ํ de octubre de 1949 en Beijing, cuando el Kuomintang ya sólo ocupaba algunas
} 
y la bomba atómica soviética que puso fin al monopolio nuclear de Estados Unidos. ${ }^{52}$

Según la apreciación del informe, presente en el texto de Suslov, el capitalismo se encontraba bajo la sombra de una nueva crisis económica inevitable por el agravamiento de sus contradicciones, la desocupación, el desempleo y la baja creciente del nivel de vida de las masas, siendo los síntomas más evidentes el "fracaso" del Plan Marshall (uno de los puntos más impactantes en el informe de Suslov), la devaluación de la libra ${ }^{53}$ y la crisis del sistema colonial; esta amenaza era lo que impulsaba la política de guerra y agresión del imperialismo. Aún más allá de la retórica de la época, usual en los documentos políticos del comunismo, el voluntarismo del análisis es evidente, y el error crucial de la argumentación consistía en la sobreestimación de la importancia de ciertos signos adversos, como el crecimiento de la inflación en la economía estadounidense a fines de la década de 1940, evaluando erróneamente las posibilidades de crecimiento capitalista y de su flexibilidad sistémica, lo que le impedía valorar

ciudades en el sur. En diciembre el líder nacionalista Jiang Jieshi se refugió en la isla de Taiwán, que de inmediato sería escenario de fuertes conflictos y de tensiones significativas a lo largo de la Guerra Fría.

${ }^{52}$ La primera bomba atómica soviética fue detonada el 29 de agosto de 1949. Sobre la sorpresa y el desconcierto del gobierno estadounidense frente al acontecimiento, que en sus cálculos más pesimistas esperaba recién para 1951 y no tenía previsiones militares al respecto, véase Tad Szulc, "Cómo consiguió la Unión Soviética la bomba atómica", El País (26 ago. 1984).

53 El 19 de septiembre de 1949 el gobierno laborista británico devaluó su moneda $40 \%$, de 4 dólares a 2.80 por libra esterlina. El movimiento también impulsó a otros gobiernos a devaluar sus monedas respecto del dólar, entre ellos Australia, Dinamarca, Irlanda, Egipto, India, Israel, Nueva Zelanda, Noruega y Sudáfrica. 
adecuadamente un proceso económico que en realidad estaba en el umbral de una inédita ola de prosperidad, los trente glorieuses años transcurridos hasta la crisis de 1973. El peso de la evocación del colapso de 1929, que en líneas generales había sido adecuadamente pronosticado por la Internacional Comunista sobre la base de las investigaciones de Eugen Varga, nubló la capacidad de diagnóstico de la coyuntura presente, y el partido comunista de México siguió dócilmente esas previsiones de los economistas soviéticos, transmitidas por Suslov en su informe, a pesar de la opinión matizada que Varga había efectuado en contrario. ${ }^{54}$

La teoría de Varga y de los economistas soviéticos retomada por el partido mexicano era la actualización de la añeja teoría del "subconsumo" como explicación de las causas de las crisis del capitalismo, o sea, la distancia creciente entre la expansión de la producción de mercancías y el consumo crecientemente limitado; la consecuencia es necesariamente la "sobreproducción" relativa de mercancías. Esta contradicción objetiva del capitalismo, agravada por el surgimiento e intensificación de la acción de los monopolios, empuja

54 Eugen Varga (Budapest, 1879-Moscú, 1964) fue el encargado de los informes económicos de la Comintern entre 1922 y 1935, y en 1928 anticipó la gran crisis del año siguiente. Desde 1930 fue asesor económico de Stalin, y asistió con esa función a la Conferencia de Postdam en 1945. En 1946 publicó La transformación económica del capitalismo al final de la Segunda Guerra Mundial, donde afirmó que el sistema capitalista era más estable de lo que se creía anteriormente, lo que motivó que el instituto que dirigía fuera clausurado, y a pesar de su autocrítica de 1949 su reputación e influencia descendió. Reapareció después de la muerte de Stalin en 1953 y predijo nuevamente el estallido de una obligada crisis económica en Estados Unidos. Para una visión conceptual positiva de la obra de Varga véase Maya Ambía, "Eugenio Varga”, pp. 171-ss. 
necesariamente a la crisis y a la exacerbación de condiciones revolucionarias por el desempleo, la disminución de la capacidad de consumo de las masas trabajadoras, la miseria generalizada. Por lo cual, la receta universal de la propaganda comunista para salir de las crisis fue la elevación de los salarios y el estímulo de la demanda, coincidiendo en este último punto esencialmente con el diagnóstico y las políticas recomendadas por Keynes para la reactivación del ciclo capitalista. El marxismo como un "keynesianismo de izquierda": nada que ver con la ley de la tendencia decreciente de la tasa de ganancia y los problemas estructurales de la reproducción y acumulación del capital relacionados con ella - insuficiente valorización del capital, disminución progresiva del volumen de beneficios con relación al capital acumulado-, que fue la piedra angular de la interpretación de Lenin. ${ }^{55}$ Por otra parte, la teoría subconsumista permitía ponderar los logros del socialismo y su superioridad como régimen social, ya que con la eliminación de la propiedad privada de los medios de producción y con su economía centralmente planificada se encontraba ajeno a las crisis recurrentes y cada vez más severas del mundo capitalista.

55 Quintana, Del romanticismo, consulta: diciembre de 2015-enero de 2016. "La crisis fundamental del capitalismo deriva entonces, no del pauperismo de las masas obreras, ni de la insuficiente demanda, ni del consumo reducido, sino de la insuficiente valorización o, lo que es lo mismo, de la sobreacumulación, de la plétora de capital: la producción se colapsa por grandes bolsas de capital (en forma tanto de dinero como de mercancías) que no se recuperan productivamente. Es un proceso dialéctico en el que las mismas causas que generan la prosperidad conducen a la depresión, porque el desarrollo de las fuerzas productivas reduce la fuente de plusvalía, que no es otra que el trabajo productivo, y obstaculiza la valoración y acumulación de capital”. Quintana, Del romanticismo, cap. 9, p. 1. 
La retórica del documento presentado por Encina alcanza sus niveles más virulentos - copia fiel de las diatribas de Gheorghiu-Dej reproducidas en diciembre de 1949 en el periódico de la Kominform - cuando se refiere al "renegado Tito", a quien tampoco le ahorra el epíteto de "provocador trotskista", "uno de los agentes más miserables y abyectos” del imperialismo:

Tito y su banda fascista constituyen el ejemplo más cínico de la traición al socialismo y al campo de la paz y la democracia. Por el camino del nacionalismo burgués, la banda de Tito ha venido desarrollando su traición al marxismo hasta convertirse hoy en un verdadero agente imperialista de guerra y provocación contra la Unión Soviética.

El corolario fue la obligada mención a los juicios en las democracias populares, en esta ocasión el de Rajk en Hungría, cuya traición ha tenido como "centro director a la banda fascista de Tito, actuando ésta bajo las instrucciones del imperialismo anglo-yanqui”. ${ }^{56}$

Apoyando las demandas del canciller soviético Andrei Vishinsky en las Naciones Unidas, el Partido Comunista

56 Encina y Valdés, Por la Paz, pp. 5-7. László Rajk (1909-1949), comunista húngaro. Participó en las Brigadas Internacionales en la guerra de España y en la resistencia antifascista. Ministro del Interior y luego de Relaciones Exteriores del régimen de democracia popular en Hungría, fue falsamente acusado de ser espía al servicio de Tito y un agente del imperialismo que planeaba la restauración del capitalismo y ponía en peligro la independencia de Hungría. Orquestado por la NKvD (policía secreta soviética) y el secretario general del Partido Comunista Húngaro, Mátyás Rákosi, el juicio se desarrolló entre el 19 y el 24 de septiembre de 1949; Rajk fue encontrado culpable, condenado a muerte con otros acusados y ejecutado el 15 de octubre. 
solicitaba la proscripción del arma atómica, el control internacional de la energía nuclear y un acuerdo de paz de las grandes potencias. Y llegaba a la definición de la idea más relevante de la actualización de su línea política, de acuerdo con la resolución de la Kominform adoptada tres semanas después de la reunión mexicana:

La lucha contra la guerra es nuestra tarea central, es la primera tarea del Partido. Si la lucha contra la guerra y por la paz es la tarea central de nuestros pueblos, es la tarea fundamental de los comunistas, dicha lucha debe estar colocada en el primer plano de la actividad diaria y constante de las masas y de su vanguardia, nuestro Partido Comunista; nosotros tenemos que subrayar que nuestro Partido, sus células y todos sus organismos, tienen el gran deber, rompiendo y liquidando las debilidades que en este sentido existen hoy en el pueblo mexicano, de impregnar la lucha de masas populares mexicanas y de sus mejores fuerzas representativas, de un alto contenido en defensa de la paz. ${ }^{57}$

\section{El XI Congreso del PCM}

Entre el 20 y el 25 de noviembre de 1950 se reunió el XI Congreso del Partido Comunista Mexicano. ${ }^{58}$ El acontecimiento dominante en el escenario internacional era el estallido de la guerra de Corea y la agresión contra la República Popular China al intervenir la flota de Estados Unidos

57 Encina y Valdés, Por la Paz, p. 10.

58 Partido Comunista Mexicano, XI Congreso. Ambos materiales reproducidos en ConcheIro y PAYÁn, Los Congresos comunistas, vol. II, pp. 9-42, edición por la que citamos. 
en el estrecho de Taiwán. ${ }^{59}$ Para el Congreso estos hechos muestran el objetivo de los círculos más agresivos del imperialismo estadounidense de incrementar "la preparación del gran crimen contra la paz del mundo", el lanzamiento de una guerra de agresión contra la URSS, las democracias populares, los pueblos coloniales que luchan por su independencia y los pueblos del mundo que defienden la paz, la democracia y la independencia nacional. Equiparado a "Hitler y sus cómplices", el imperialismo está dispuesto a desatar una "guerra de agresión y rapiña", a pasar de los preparativos a la acción, apoderándose de toda Corea para convertirla en una colonia, con un "régimen antipopular sanguinario y represivo, a imagen y semejanza del que regentea el verdugo

${ }^{59}$ La guerra de Corea estalló el 25 de junio de 1950, cuando las tropas de Kim Il Sung atravesaron el paralelo $38^{\circ}$ (línea de partición de los dos estados coreanos) y ocuparon casi toda la península. Hubo una inmediata reacción de Estados Unidos, con un mandato del Consejo de Seguridad de la ONu, logrado por la ausencia del representante soviético que había rechazado asistir a las reuniones del Consejo como protesta por la negativa estadounidense de aceptar a China Popular en él. Las tropas estadounidenses recuperaron el territorio perdido y avanzaron a su vez hacia el norte; el 19 de octubre tomaron Pyongyang, la capital de Corea del Norte. Tres días antes, el 16 de octubre, tropas chinas con apoyo militar soviético penetraron en Corea haciendo retroceder al ejército estadounidense. Esta era la situación en el momento de la reunión del Comité Central mexicano. El 4 de enero de 1951, las tropas comunistas retomaron Seúl. La Unión Soviética manifestó su intención de no intervenir directamente en el conflicto y su deseo de que coexistieran dos sistemas sociales diferentes en la península. La guerra se extendió hasta 1953, cuando se firmó un armisticio todavía vigente. La alusión de Encina a una agresión a China Popular obedeció a la oferta de Estados Unidos de apoyo militar a Taiwán, después del estallido de la guerra en Corea, consistente en tropas estacionadas en la isla y navíos de la Séptima Flota que patrullaban el estrecho de Taiwán para evitar una supuesta invasión comunista de la isla. 
Sygman Rhee", ${ }^{60}$ amenazando Manchuria, para lograr una base de agresión directa contra China y la URSS, apoderarse de Formosa (Taiwán) y aplastar la lucha del pueblo de Vietnam, Indochina, Malasia y Filipinas.

La agresión en Corea, que Estados Unidos cubrió con ilegales resoluciones del Consejo de Seguridad de las Naciones Unidas, organización convertida en herramienta del expansionismo y la agresión, intensificó la respuesta de

[...] millones y millones de hombres y mujeres de todos los países que están dispuestos a detener las desbocadas agresiones del imperialismo yanqui y parar la guerra [...] las fuerzas partidarias de la paz están dispuestas a atar las manos de los agresores y a despedazar sus planes de guerra y dominación mundial. ${ }^{61}$

La conclusión del análisis de la situación internacional efectuado por el XI Congreso fue que el campo de la paz, de la democracia y del socialismo encabezado por la Unión Soviética se había fortalecido y la correlación internacional de fuerzas seguía modificándose a su favor. La resolución de la reunión efectuó un exhaustivo recuento de los hechos que sustentaban ese diagnóstico. En primer lugar, la consolidación de la potencia económica y militar de la Unión Soviética, el afianzamiento económico y político de los países de

60 Sygman Rhee (1875-1965), político surcoreano, líder nacionalista, conservador y anticomunista, primer presidente de Corea del Sur de 1948 a 1960. Partido Comunista Mexicano, XI Congreso; Concheiro y PaYán, Los Congresos comunistas, vol. II, p. 16.

${ }^{61}$ Partido Comunista Mexicano, XI Congreso; Concheiro y Payán, Los Congresos comunistas, vol. II, p. 17. 
democracia popular "que marchan resueltos por la vía del socialismo", la creación de la República Democrática de Alemania, el pacto de amistad y ayuda mutua entre la República Popular China y la Unión Soviética, la consolidación y aumento de la influencia de los partidos comunistas de las grandes potencias capitalistas, el desarrollo del movimiento obrero y la "consolidación combativa" de la organización sindical mundial del proletariado, el reforzamiento de las luchas de liberación nacional en los países coloniales y en el gran crecimiento del movimiento mundial por la paz. A la vez, el campo del "putrefacto sistema capitalista" se debilita continuamente, acosado por la crisis general del capitalismo. En síntesis, una lectura cuidadosa del informe Suslov actualizado por los análisis e instrucciones de la Kominform en su periódico.

\section{TRES REUNIONES POR LA PAZ, 1948-1949: \\ BRESLAVIA, PARÍS, MÉXICO}

\section{Breslavia}

El poeta polaco Jerzy Boreszja, traductor de Pablo Neruda, ${ }^{62}$ impulsó a comienzos de 1948 la idea de una reunión de intelectuales con el objetivo de pedir la supresión del arma

${ }^{62}$ Jerzy Boreszja fue un activista de la reconstrucción de Polonia después de la guerra; impulsó la actividad editorial en Varsovia. Tradujo "Que despierte el leñador”, de Neruda, en colaboración con Lech Pijanowski. Falleció en 1952 y Neruda escribió un obituario: "Se fue Jerzy Boreszja", El Nacional (22 ago. 1952). Un relato de la amistad entre ambos, anudada en la visita del escritor chileno a Polonia en julio de 1949, en Sanhueza, "Neruda", p. 202. 
nuclear y el trabajo conjunto de las grandes potencias por la distensión y la paz. Con el discreto apoyo del aparato de propaganda de la Kominform la iniciativa creció y renombrados escritores, artistas y científicos se encontraron entre el 25 y el 28 de agosto de ese año en Breslavia - hasta 1945 Breslau, transferida de Alemania a Polonia - en el Congreso Mundial de Intelectuales por la Paz. Asistieron, entre muchas personalidades destacadas, Paul Eluard, Irène Joliot-Curie, Julian Huxley (director general de la UNEsco), Fernand Léger; por México lo hicieron Leopoldo Méndez, del Taller de la Gráfica Popular y Raúl Cacho, de la Sociedad para el Impulso de las Artes Gráficas. ${ }^{63}$ Los pacifistas se reunieron en un notable edificio de hormigón, inaugurado por el káiser Guillermo II en 1913, relevante muestra de la arquitectura del siglo xx en un contexto barroco que todavía exhibía terribles marcas de la guerra: la Hala Ludova (Sala del Pueblo), rebautizada, al igual que la ciudad, por la democracia popular polaca, antes la Jabrbunderthalle (Sala del Centenario), construida para conmemorar el centenario de la victoria sobre Napoleón en Leipzig. Pablo Picasso, quien superó por primera vez su aversión al avión para llegar a la cita, pronunció el día 27 uno de los muy escasos discursos públicos de su vida, en lo que fue uno de los momentos estelares de la reunión bajo la colosal cúpula diseñada por Max Berg, en el que pidió por la libertad de expresión y movimientos de Pablo Neruda, senador del PC chileno proscrito por el gobierno de González Videla,

[...] un amigo que debería estar aquí [...] el más grande poeta de la lengua española y uno de los más grandes poetas del

${ }^{63}$ Fernández Montes, “Voces”, p. 4. 
mundo, que ha tomado siempre el partido de los hombres despreciados, Pablo Neruda, perseguido por la policía de Chile, acorralado como un perro [....$^{64}$

Picasso dejó en una de las paredes de la Hala Ludova la primera de su gran serie de palomas de la paz, que a partir de la versión impresa en el cartel anunciando el Congreso de París, seleccionada por Aragon, el escritor surrealista y militante del Partido Comunista Francés (PCF), alcanzaría un valor icónico universal.

Como iniciativa de esta reunión se estableció el Buró Internacional de Enlace de los Intelectuales en Defensa de la Paz y se convocó al Primer Congreso Mundial de Partidarios de la Paz, a reunirse en abril de 1949 en París. ${ }^{65}$ La convocatoria originada en Breslavia se consolidó rápidamente. La Federación Internacional Democrática de Mujeres e importantes personalidades intelectuales y políticas llamaron a la concreción del Congreso Mundial por la Paz. En México, el periódico comunista transcribió el llamamiento oficial al congreso y el expresidente Lázaro Cárdenas se adhirió por telegrama a la iniciativa. ${ }^{66}$

Se dio inicio así a una de las mayores campañas de propaganda política en el siglo xx, que se convirtió en uno de los instrumentos más importantes del movimiento comunista

${ }^{64}$ Hay varias versiones del discurso de Picasso, pero todas coinciden en lo esencial de su contenido. Véase la nota de Pierre Hervé en L'Humanité (28 ago. 1948); SANHUEZA, "Neruda”, p. 198, reproduce el texto según fue publicado en la revista Pro-Arte (28 nov. 1952), Santiago de Chile; OlivaRes Briones, Pablo Neruda; Nicolas, "Picasso". El artículo original se publicó en la revista Projet, Varsovia, 1965.

${ }^{65}$ Fernández Montes, "Voces", p. 3.

${ }^{66}$ La Voz de México (14 mar. 1949), pp. 1, 3. 
internacional en la Guerra Fría por medio de las acciones de múltiples organizaciones del Movimiento por la Paz, planificado y coordinado por la Kominform, en especial a partir de 1949, como ya señalamos. Se aprovechaba la enorme experiencia organizativa y de propaganda acumulada por la Internacional Comunista en la década de 1920 y en los años de la lucha antifascista, sobre todo la del mítico Willi Münzenberg, el secretario de propaganda en Europa occidental, y sus campañas por el hambre en Rusia en 1921, la Liga contra el Imperialismo, el Comité Internacional contra la Guerra y el Fascismo, la defensa de Sacco y Vanzetti y el contrajuicio por el incendio del Reichstag, que logró la absolución de Dimitrov en $1933 .{ }^{67}$ En términos de la lucha por la paz y la defensa de la URSS también había antecedentes importantes: Rolland y Barbusse organizaron el Congreso Internacional contra la Guerra y el Fascismo, reunido en Ámsterdam en agosto de 1932 para frenar la amenaza de Japón contra la URSS por la ocupación de Manchuria. Los delegados que acudieron a Ámsterdam en 1932 representaban a más de 30000 organizaciones, y se publicó un manifiesto de los "trabajadores intelectuales y manuales" contra la guerra y el fascismo, contra las naciones que preconizaban la guerra y por la defensa de la URSS. A principios de junio de 1933 tuvo lugar en la Sala Pleyel de París el Congreso Antifascista Europeo, que aprobó la creación del Comité de Lucha contra la Guerra y el Fascismo.

${ }^{67}$ Una insuperable descripción del trabajo de propaganda y organización de la Komintern, aplicado luego por el Movimiento por la Paz en KoestLER, La escritura. Koestler fue un estrecho colaborador de Münzenberg en la lucha antifascista. 
París

El Congreso Mundial de Partidarios de la Paz se reunió en París del 20 al 28 de abril de 1949 en la histórica Sala Pleyel, convocado por 75 intelectuales de 17 países. ${ }^{68}$ Participaron 2895 delegados de 72 naciones, y se realizó una sesión paralela en Praga para los representantes que no lograron obtener la visa francesa. Lo presidió el eminente científico Frédéric Joliot-Curie, premio Nobel de Química (en 1935, junto con su esposa Irène Curie, también militante pacifista) y Alto Comisionado de la Comisión de Energía Atómica de Francia. ${ }^{69}$ Numerosas personalidades de la literatura, las artes, la filosofía, las ciencias sociales, la historia, agrupaciones religiosas, organizaciones sociales y figuras políticas se encontraron presentes, y un listado somero de algunos asistentes da una buena idea de la amplitud de la convocatoria y la resonancia de las cuestiones planteadas. Por Francia, la delegación más numerosa, se encontraban Yves Fargue, Paul Eluard, Louis Aragon, Elsa Triolet, Eugénie Cotton, Jean Cassou, Aimé Cesaire, Pierre Cot, Paul Rivet, Armand

${ }_{68}$ La Voz de México (24 abr. 1949), p. 1.

${ }^{69}$ Frédéric Joliot-Curie (1900-1958). Científico eminente, una de las grandes figuras de la investigación del átomo, construyó en 1937 el segundo ciclotrón de Europa en el Colegio de Francia, después de la Unión Soviética, y el primer reactor nuclear francés en 1948, que terminó con el monopolio anglosajón. Premio Stalin de la Paz 1951, militó en el antifascismo, en la Resistencia y en el Partido Comunista Francés desde 1942, siendo miembro de su Comité Central durante 1956-1958. En 1950 el primer ministro Bidault lo destituyó de su cargo de Alto Comisionado de la Energía Atómica francesa por su militancia comunista, y unos meses más tarde también fue expulsada su esposa Irène de la Comisión de Energía Atómica. 
Salacrou, Pierre Seghers, Pablo Picasso; por Italia, Pietro Nenni, Elio Vitorini, Italo Calvino, Renato Guttuso, Giulio Einaudi, Emilio Sereni; por Alemania, Anna Seghers, Arnold Zweig; por Estados Unidos, Charlie Chaplin, Howard Fast, Langston Hughes, Paul Robeson, Albert Kahn, W. E. B. DuBois; por la URSS, Ilya Ehrenburg, Míjail Shólojov, Alexandr Fadéiev, Wanda Wassilewska, Dimitri Shostakóvich; por Yugoeslavia, Ivo Andric; por China, Kuo Mo Jo, E Mi Siao. Latinoamérica y los países del Caribe fueron representados por 150 delegados de 16 naciones: 21 de Argentina, 12 de Brasil, 12 de Cuba, 10 de Venezuela, 8 de Haití, 6 de Guatemala, 6 de México, 4 de Canadá, 3 de Bolivia, 3 de Colombia, 3 de Uruguay, 2 de Chile, 2 de Puerto Rico, 1 de Costa Rica, 1 de Ecuador y 1 de Jamaica. ${ }^{70}$ Entre las personalidades relevantes de México se encontraban Narciso Bassols, Dionisio Encina y Vicente Lombardo Toledano; Antonio Berni, Luis Seoane y Alfredo Varela por Argentina; Jorge Amado y Caio Prado Jr. por Brasil; Nicolás Guillén y Juan Marinello por Cuba; Luis Cardoza y Aragón y Manuel Fortuny por Guatemala; René Depestre por Haití, Miguel Otero Silva y Héctor Poleo por Venezuela. ${ }^{71}$

No faltó al Congreso su cuota de espectacularidad, su golpe de efecto al estilo Münzenberg, tal como lo narra Volodia Teitelboim:

El 25 de abril de 1949 se celebra en la Sala Pleyel la clausura del Congreso Mundial de Partidarios de la Paz. [...] Meses antes, en Chile, tras la interdicción del Partido Comunista chileno

\footnotetext{
70 Sanhueza, “Neruda”, las referencias al Congreso de París en pp. 197-199. 71 Sanhueza, "Neruda”, personalidades presentes, p. 197. El listado tiene algunos errores.
} 
por orden del Presidente que había sido elegido gracias a la alianza con ellos, fueron encarcelados ministros y representantes comunistas, traición denunciada por Neruda, entonces senador comunista, quien acto seguido pasó a ser el enemigo público número uno, sumido en una rotunda clandestinidad.

Sólo un puñado de personas sabía de su paradero, Neruda se convirtió en un símbolo desatando, en medio de la Guerra Fría como antecedente del macartismo en los Estados Unidos meses después, una ola de solidaridad internacional. La manera en que dejó Chile, cruzando una frontera improbable de la cordillera chileno argentina disfrazado de arriero, y de cómo apareció de la noche a la mañana en París es toda una leyenda. Luego de meses de absoluta incertidumbre Picasso anuncia a los organizadores, aquel día de clausura en la Sala Pleyel, que tiene una sorpresa.

Preside esta última sesión Yves Fargue, quien anuncia, con tono intencionado: Voy a dar la palabra al último orador, que va a cerrar la discusión general. El hombre que va a hablarles está sólo desde hace unos minutos en la sala. Ustedes no lo han visto todavía. Es un hombre perseguido. Es Pablo Neruda.

Todos los asistentes se ponen de pie. No contaban con esta descarga eléctrica dentro del teatro. Neruda hace un discurso corto, en que aparece como disculpándose por la tardanza. Queridos amigos dice, si he llegado con algo de retraso a vuestra reunión, se ha debido a las dificultades que he tenido que vencer para llegar hasta aquí. A todos ustedes les traigo el saludo de gentes de tierras lejanas. La persecución política que existe en mi país me ha permitido apreciar que la solidaridad humana es más grande que todas las barreras, más fácil que todos los valles. ${ }^{72}$

72 Teitelboim, Neruda, s. p.; Sanhueza, “Neruda”, pp. 197-198. Howard Fast, quien en un artículo escribió que Neruda "se había transformado en leyenda" y Anna Seghers, entre otros, han dejado testimonios del impacto y entusiasmo que despertó Neruda en el Congreso. Schidlowsky, Pablo Neruda, relata todas las andanzas de Neruda para llegar al Congreso, 
El debate abordó el fin de la carrera armamentista, el papel de las Naciones Unidas en la defensa de la paz, la denuncia de la propaganda de guerra, el respeto de la soberanía y la independencia de los pueblos, la libertad de relaciones económicas entre las naciones, la participación de la mujer en los movimientos de paz y la organización de los partidarios de la paz. La presidencia del Congreso incluyó también en las sesiones los temas relativos a la defensa de la cultura, las guerras coloniales y el papel de la juventud en la lucha por la paz. Por medio del Manifiesto del Congreso los pueblos del mundo, "a todos los cuales concierne la defensa de la paz”, señalan que a cuatro años de finalizada la tragedia nuevamente están afectados por una carrera armamentista y por la guerra. Con obvio destinatario, el documento afirma que los pueblos conocen a quienes han violado los acuerdos entre las grandes potencias para garantizar la coexistencia de distintos sistemas sociales y la Carta de las Naciones Unidas, y también a quienes piensan que los acuerdos que preservan la paz entre los pueblos son sólo trozos de papel; quienes rechazan las negociaciones y el desarme, se arman hasta los dientes y se colocan en el papel de agresores. Por ello se denuncia el arma nuclear, se condenan las alianzas militares, el rearme de Alemania Occidental y Japón y la deliberada interrupción de relaciones económicas con un grupo de países, que adquiere el carácter de bloqueo militar. Los instigadores de la Guerra Fría, dice el Manifiesto, han pasado de sólo teatralizar la guerra a prepararla abiertamente.

pp. 778-785; testimonio de Fast, pp. 783-784, y de Seghers, pp. 784-785, nota 13. Otra versión de la historia de la aparición de Neruda en París en Amorós, Neruda, cap. 8, s. p. 
El manifiesto declaraba que se lucharía por la proscripción del arma atómica y las demás armas de destrucción masiva, por la reducción del armamento de las grandes potencias y el establecimiento de mecanismos de control internacional con el objetivo de que la energía nuclear fuese utiliza$\mathrm{da}$ con fines exclusivamente pacíficos y de bienestar humano. Se lucharía también por la independencia nacional y la pacífica cooperación entre los pueblos, por el derecho de las naciones a la autodeterminación - que constituía la principal condición para la paz y la libertad - y contra las restricciones a las libertades democráticas. Se denunciaba la histeria belicista, el odio racial y el fomento de la enemistad entre los pueblos. El Congreso también resolvió condenar y boicotear todos los medios utilizados por los belicistas para sus fines: libros, películas y periódicos, así como a individuos y organizaciones que hicieran propaganda bélica o incitasen a una nueva guerra. Y, finalmente, se convoca a ganar "la batalla por la paz, la batalla por la vida". ${ }^{73}$

También el Congreso acordó crear un Comité del Congreso Mundial de la Paz cuya misión sería promover el Movimiento de Partidarios de la Paz, instituyéndose también el Consejo Mundial de la Paz, cuyo primer presidente fue Fréderic Joliot-Curie. Destacadas personalidades democráticas "que forman la avanzada de sus pueblos en la lucha por la paz”, como los definió el órgano comunista mexicano $L a$ Voz de México, integraron el Comité: Frédéric Joliot-Curie, su esposa Irène; el doctor Hewlett Johnson, el “Deán Rojo" de Canterbury; O. John Rogge, exayudante del procurador

73 El texto del Manifiesto del Congreso en ;Por una paz duradera, por una democracia popular!, 1ํㅡㄹ Mayo, 1949, núm. 9 (36). Dispusimos de la versión en inglés del periódico de la Kominform. 
de Justicia de Estados Unidos e investigador de la presencia nazi en Estados Unidos; el escritor Howard Fast; el doctor W. E. B. Dubois, historiador afroamericano, ensayista y militante de los derechos civiles; Paul Robeson, cantante negro; Donald Henderson, militante comunista y dirigente obrero de Estados Unidos; Mrs. Gane Weltfish, antropóloga estadounidense perseguida luego por el macartismo; el reverendo Arthur W. Moulton, obispo epicopal; Vicente Lombardo Toledano, presidente de la Confederación de Trabajadores de América Latina. ${ }^{74}$

El PCM se hizo eco inmediato de la reunión de París. El periódico comunista inició la crónica del congreso con una declaración hiperbólica: "un éxito grandioso, que asesta a los provocadores de la guerra y al campo imperialista de la agresión armada contra los pueblos un golpe decisivo". La misma retórica atraviesa toda la nota, que culmina afirmando:

El Congreso de París fue la expresión de odio, condena y rechazo enérgico a los planes de agresión mundial contra la paz y la libertad de todos los pueblos que alimenta el imperialismo yanqui y sus satélites. En él, lo mejor, lo más puro, generoso y noble de la humanidad ha unido sus fuerzas para la lucha por la paz, que inicia una nueva y gigantesca etapa: la movilización mundial organizada y unida para imponer a los provocadores de la guerra la voluntad unánime y enérgica de paz que anima a todos los pueblos. ${ }^{75}$

Dionisio Encina, que representó en París a la Unión de Sociedades de Crédito Ejidal de la Comarca Lagunera, fue

\footnotetext{
74 La Voz de México (1ํ mayo 1949).

75 La Voz de México (1ํo mayo 1949).
} 
entrevistado a su regreso por $L a$ Voz de México, a fin de captar sus impresiones acerca del "gran acontecimiento mundial".

El Congreso de Partidarios de la Paz, ha sido la Asamblea Mundial más grande que hasta ahora se haya celebrado, puesto que nunca antes estuvieron reunidas las fuerzas populares del mundo entero en número tan grande y de tan alta calidad [...] enfatizó Encina al comenzar la entrevista. El Congreso demostró que fuerzas democráticas defensoras de la paz en el mundo, son infinitamente poderosas, ya que pese a las medidas represivas y a la intensa propaganda desplegadas por el gobierno de Francia (negó el visado a 380 delegados de diez países que se vieron obligados a realizar un congreso paralelo al de París, en la ciudad de Praga), y por la prensa del mismo país contra el Congreso, estuvieron representados en él 600 millones de seres a través de dos mil delegados de setenta y dos países [...] Los resultados del Congreso superaron a todas las previsiones. El éxito de la gran asamblea no era esperado en una forma tan esplendorosa. Durante el periodo de preparación no se pudo pensar en el grandioso resultado. ${ }^{76}$

Encina afirmó que el Congreso demostró el acierto del camarada Zdhánov cuando señalaba en su informe en la sesión constitutiva del Kominform que el campo democrático y de la paz es más poderoso que el del imperialismo y la reacción y - ya experimentado en el ceremonial comunista - el secretario del PCM no eludió la formalidad de aludir a los dos partidos más poderosos de Occidente y destacó la masividad de los delegados de Francia e Italia y la forma democrática de su

76 "Las fuerzas de la paz demostraron en París que son infinitamente poderosas” (entrevista a Dionisio Encina), La Voz de México (29 mayo 1949), pp. 1, 3. 
elección. También subrayó la enorme movilización de masas que rodeó al Congreso en la capital francesa, en un acto de clausura con la presencia de más de medio millón de personas.

París vivió durante una semana con la atención puesta en los resultados del Congreso. Las casas tenían sus fachadas adornadas con banderas de los diferentes países representados; las personas mostraban en sus pechos los distintivos del Congreso; en las calles se hablaba constantemente de los trabajos de la gran Asamblea; numerosas delegaciones de obreros y de los habitantes de los barrios llegaban constantemente a la Sala Pleyel, a presentar saludos al Congreso. ${ }^{77}$

El funcionario comunista también afirmó que la semana de trabajos del Congreso de la Paz arrojó resultados de extraordinaria importancia para los partidarios de la paz en todo el mundo, subrayando que el Congreso resolvió realizar la más intensa divulgación de las resoluciones y del contenido de la Asamblea; desenmascarar todos los preparativos guerreristas de los círculos imperialistas; construir comités permanentes de lucha por la paz y contra la guerra, mediante la celebración de congresos regionales o nacionales; aprobó un llamado a los católicos suscrito por los ministros cristianos de diversas iglesias y aprobó también una moción de apoyo al pueblo español en su lucha contra la dictadura fascista de Franco.

En la misma entrevista de La Voz de México Dionisio Encina anunció la iniciativa de celebrar el Congreso Continental por la Paz y contra la Guerra. La convocatoria se

${ }_{77}$ La cita textual y las referencias anteriores en "Las fuerzas de la paz demostraron en París que son infinitamente poderosas" (entrevista a Dionisio Encina), La Voz de México (29 mayo 1949). 
efectuaría con las mismas bases del Congreso de París, con la denuncia de la carrera armamentista, el apoyo al papel de la Organización de las Naciones Unidas en defensa de la paz, la denuncia de los preparativos bélicos que realizan los círculos guerreristas del mundo, el respeto a la soberanía y a la independencia de los pueblos, la apertura de relaciones económicas entre todas las naciones y la participación de las mujeres y la juventud en el movimiento de la paz. ${ }^{78}$

\section{México: el Congreso Continental de Partidarios de la Paz}

El Congreso Continental por la Paz se realizó dentro de una política general de realización de esas reuniones, como continuación de los congresos por la Paz de Breslavia, Nueva York, París y Moscú..$^{79} \mathrm{La}$ convocatoria para el Congreso Continental Americano por la Paz se publicó en el periódico El Tiempo el 19 de agosto de 1949. La firmaron Diego Rivera, David Alfaro Siqueiros y Alfonso Reyes, por México; Oscar Niemeyer y Graciliano Ramos por Brasil; Augusto D’Halmar, Carlos Ibáñez, Claudio Arrau, Salvador Allende y Alejandro Lipschütz por Chile; Baldomero Sanín Cano por Colombia; Nicolás Guillén por Cuba; Manuel Otero Silva por Venezuela; Thomas Mann, Arthur Schnabel, Howard Fast, Stefan Heym, Dashiell Hammett y Dorothy Parker por Estados Unidos, y muchos otros escritores y artistas. ${ }^{80}$

\footnotetext{
78 "Las fuerzas de la paz demostraron en París que son infinitamente poderosas" (entrevista a Dionisio Encina), La Voz de México (29 mayo 1949), pp. 1, 3. La entrevista a Encina fue realizada al regresar éste de París por Gilberto U. Lirquen, jefe de redacción del periódico comunista.

79 Encina y Valdés, Por la Paz, p. 5.

${ }^{80}$ El Tiempo (19 ago. 1949).
} 
El Congreso se inauguró en la noche del 5 de agosto de 1949 en la Arena Coliseo de la Ciudad de México. El presidente fue el poeta Enrique González Martínez y asistieron unos 1500 delegados.

El general Lázaro Cárdenas envió un mensaje al Congreso en el que expresó:

Quienes anhelamos una paz constructiva, libre de miserias y opresiones, comprendemos la necesidad de unirnos para mantener la respetabilidad de los Tratados Internacionales [Cárdenas menciona la carta de las Naciones Unidas y de la Organización de Estados Americanos] amenazados por los que se empeñan en anular la victoria de las democracias con una tercera guerra mundial [...] El menoscabo de los principios internacionales pactados, implica una grave amenaza para la seguridad y prosperidad colectivas. El permanecer indiferente o no esgrimir todos los medios disponibles para evitar la guerra, que sólo traería nuevos y estériles sacrificios y desolación para los pueblos, significaría ser víctimas de una inconsciencia suicida e incurrir en una criminal responsabilidad. ${ }^{81}$

El expresidente criticó el incremento de la industria armamentista, la firma de acuerdos regionales y alianzas militares sin que se hubiesen firmado los tratados de paz definitivos de la pasada guerra, la "indiferencia [ante] la reconquista popular de España” y el "rearme de los vencidos” en la pasada guerra, con lo que expresaba la línea usual de los organizadores del Congreso contra el imperialismo de Estados Unidos y sus aliados. Sin embargo, en un par de párrafos

${ }^{81}$ El texto completo del mensaje fechado en Pátzcuaro el 5 de septiembre de 1949, en El Popular (6 sep. 1949). 
Cárdenas expresaba críticas que en su ambigüedad bien podrían entenderse como dirigidas a la URSS: "deben abatirse todas las ambiciones de hegemonía para no incurrir en menosprecio de la voluntad de los pueblos" y el ejercicio de "tácticas de servidumbre contra naciones que lucharon por el aniquilamiento de las tiranías y la edificación de una paz perdurable". 82

La posición de mayor perspectiva presentada en el Congreso estuvo a cargo del doctor Linus Pauling, ${ }^{83}$ quien junto con el doctor James G. Endicott, ${ }^{84}$ delegado por Canadá,

${ }^{82}$ El Popular (6 sep. 1949); en la primera cita las cursivas son mías H.C.; en la segunda, Cárdenas podría estar aludiendo a las relaciones de la URSS con Polonia, Checoslovaquia e, incluso, con la Yugoslavia del mariscal Tito.

${ }^{83}$ Linus Pauling (1901-1994). Se negó a trabajar en el Proyecto Manhattan de construcción de la bomba atómica. Es el único ganador individual de dos premios Nobel: de Química en 1954 y de la Paz en 1962, este último "en reconocimiento por sus esfuerzos por buscar un tratado de proscripción de pruebas nucleares [por su trabajo] no sólo contra las pruebas de armas nucleares, no sólo contra la proliferación de dicho armamento, no sólo contra su uso, sino contra la guerra como medio de solventar los conflictos internacionales", según la declaración oficial. Premio Lenin de la Paz en 1970. Fue hostigado durante el macartismo por el Departamento de Estado, entre otras agencias gubernamentales, que le retiró temporalmente el pasaporte en 1952. Extraordinario científico, hizo contribuciones notables en mecánica cuántica, química cuántica, química orgánica e inorgánica, bioquímica y medicina, y en las zonas de contacto de todos estos campos. Fue uno de los fundadores de la biología molecular.

${ }^{84}$ James Gareth Endicott (1888-1893) fue un clérigo canadiense, nacido en China en una familia de misioneros. Entre 1925 y 1947 fue misionero en China, asesor de Jiang Jieshi y enlace entre la misión militar estadounidense y las fuerzas comunistas en la lucha contra los japoneses. Desilusionado del Kuomintang, apoyó al PCCH en la guerra civil y colaboró con Zhou Enlai. Regresó a Canadá en 1947 y continuó con ese apoyo. En 1949 fundó y dirigió el Congreso Canadiense de la Paz y se convirtió en una importante 
solicitó que las Naciones Unidas tuvieran el control de las armas nucleares. El pacifista canadiense afirmó que la amenaza a la paz proviene de Wall Street y del imperialismo: "Exigimos - dijo - que las bombas atómicas fabricadas en Canadá sean encerradas bajo llave y puestas al cuidado de las Naciones Unidas". ${ }^{85}$ Pauling era uno de los ocho miembros del Comité de Emergencia de Científicos Atómicos creado en 1946 a iniciativa de Albert Einstein y Léo Szilárd para concientizar de los peligros del armamento, fomentar el uso pacífico de la energía nuclear y trabajar por la paz mundial como único medio de que el armamento atómico no fuese utilizado nunca más. La petición en el Congreso se enhebraba con la incesante campaña de Pauling contra las armas nucleares y su proliferación, y culminaría en 1958 con una carta suya a la ONU, firmada por más de 11000 científicos, solicitando la prohibición de las pruebas nucleares. Esto contribuyó a la moratoria de esas pruebas y a que en 1963 se firmara el Tratado de Prohibición Parcial de Pruebas Nucleares en la Atmósfera, el Espacio Exterior y Submarinas, por la URSS, Estados Unidos, Reino Unido y otros 110 países. Dos de las grandes potencias - Francia y la República Popular China - no la signaron, y se convirtieron en estados nucleares poco después.

El manifiesto final del Congreso Continental por la Paz señaló en el preámbulo de sus resoluciones la necesidad de respetar la Carta del Atlántico y los acuerdos de Moscú, Teherán, Yalta y Postdam, ya que la lucha por la paz era la

figura del movimiento internacional por la paz. En 1952 fue Premio Stalin de la Paz y entre 1957 y 1971 fue presidente de Instituto Internacional por la Paz. Apoyó a China en su conflicto con la URSS.

${ }^{85}$ El Popular (6 sep. 1949). 
continuación de la guerra contra el nazifascismo, señalando al régimen de Franco como una supervivencia del fascismo y que el rearme de Alemania y Japón significaba un potencial peligro de guerra. Se expresó que la soberanía y la independencia nacionales de los pueblos de América Latina y Canadá estaban amenazadas por los preparativos de una nueva guerra. Las resoluciones del Congreso estuvieron dirigidas a sostener los postulados de los documentos mencionados, la abolición del Pacto del Atlántico (OTAN) y del Tratado de Río de Janeiro, la lucha por la prohibición de las armas atómicas y de destrucción masiva, el llamado a los gobiernos y a los pueblos para que rechacen la política de bloques agresivos y reclamen un entendimiento entre Estados Unidos, el Reino Unido y la URSS. El Congreso llamó a los países a denunciar las medidas económicas, políticas y militares que tendieran a preparar una nueva guerra y a resistir a la carrera armamentista; requirió a los pueblos de América a enfrentar a la subordinación de la economía de sus países a fines bélicos, a "oponerse con energía a las persecuciones medievales contra la libertad de conciencia, de pensamiento y de expresión", y a levantar "una barrera infranqueable" a la discriminación racial y nacional. Pidió a los pueblos que rechazaran los ataques a la unidad de la clase obrera y de los campesinos, y que condenaran la propaganda de guerra, el régimen de Franco y el coloniaje. Finalmente, se convocó a reforzar la lucha popular por la paz y la democracia y a disponer la coordinación del movimiento de paz de cada país con el movimiento de todo el planeta por medio del comité creado por el Congreso de París. ${ }^{86}$

${ }^{86}$ El Popular (11 sep. 1949). 


\section{EPÍLOGO. LA POLÍTICA DE LA PAZ Y LOS MILITANTES DEL PCM}

Hasta aquí hemos seguido lo que Carr, críticamente, llama "la política del Comité Central", el accionar de la dirección y el desarrollo de las luchas internas.$^{87}$ ¿Cómo respondieron las organizaciones intermedias y la base del partido a la convocatoria de la lucha por la paz? Estas son preguntas cuyas respuestas son difíciles todavía, faltan estudios específicos acerca del PCM en la época abordada, en su composición social, inserción, accionar cotidiano y sus diversos sectores y comités regionales, y también de las organizaciones "de frente", de las que hemos visto apenas un resultado mediante el Congreso Continental.

Poco después de los acontecimientos aquí narrados, Victorio Codovilla, en ese entonces al frente del Partido Comunista Argentino, planteó la práctica correcta que deberían adoptar los militantes para aplicar la política comunista de la paz:

Al mismo tiempo que los comunistas deben luchar dentro del movimiento de los partidarios de la paz contra toda tendencia sectaria y demostrar que son los campeones de la coordinación de todas las fuerzas amantes de la paz, deben realizar una campaña de esclarecimiento respecto a quiénes son los que quieren la paz y quienes son los que quieren la guerra, quiénes forman en el campo de la paz y quienes forman en el campo de la guerra; quiénes son los agresores y quiénes son los agredidos en las guerras en curso (Vietnam, Corea, etc.) y quiénes son los que luchan para apagar los focos de guerra ya encendidos y quién los anima con vistas a su extensión, a fin de que si

${ }^{87}$ CARr, "Hacia”, p. 576. 
llegara a estallar la tercera guerra mundial, cada uno sepa ocupar el lugar que le corresponde en defensa de los intereses de su clase, de su pueblo, de su nación y de la paz mundial. ${ }^{88}$

La claridad pedagógica de Codovilla intentaba salir al encuentro de las dificultades múltiples de la aplicación de una línea que no entroncaba, o lo hacía con muchas dificultades, con las preocupaciones cotidianas de las masas populares y de los propios militantes de los partidos comunistas. La intervención de J. Encarnación Valdés, secretario de organización del PCM, ${ }^{89}$ en el XI Congreso abordó con mucho detalle la cuestión. Por sus funciones el secretario de organización ocupaba un lugar crucial para calibrar el entusiasmo de los militantes en la aplicación de la línea del partido, su dedicación y esfuerzos, y el cumplimiento de algunas metas específicas de acción, en este caso la recolección de firmas por el llamamiento de la paz de Estocolmo, lanzado por el Movimiento de Partidarios de la Paz en marzo de 1950, para convocar a un nuevo Congreso de los Pueblos por la Paz contra el empleo de la bomba atómica y las armas de destrucción masiva. Las observaciones de la intervención, aunque destaca el hecho -dudoso y contradictorio con el análisis efectuado - de haber logrado 700000 firmas, son

88 Codovilla, La situación, pp. 45-46.

89 VAldÉs, “Traducir”. J. Encarnación Valdés, hijo de un obrero electricista, fue secretario de organización del PCM bajo la dirección de Encina. Cuando Encina salió de la dirección, Chon Valdés fue elegido al Comité Central en el XIII Congreso, pero ya no quiso participar. Se marchó a Sinaloa a trabajar en el Seguro Social. Comunicación personal de Enrique Semo, 2 de diciembre de 2015. 
desoladoras en cuanto a la respuesta de la base del partido. En su punto medular afirma:

Entre los aspectos negativos generales de nuestro trabajo en favor de la paz, hemos de señalar que no hemos sido capaces de enrolar en esta lucha al grueso de la clase obrera; que no hemos englobado a una serie de personalidades que podían haber ampliado considerablemente el movimiento por la paz; entre los campesinos, nuestro trabajo ha sido muy raquítico [...] no hemos orientado firmemente el trabajo de las células para realizar el trabajo de la paz en forma organizada [...] no hemos logrado organizar Comités de fábrica [...] en general, podemos decir que el gran retraso en que se encuentra el trabajo de la lucha por la paz en nuestro país, se debe fundamentalmente a que el Partido en su conjunto no ha comprendido la importancia de la tarea y no ha sido puesta al centro de todas las actividades de los comunistas, al centro de todo su trabajo. ${ }^{90}$

La reflexión permite observar la distancia existente entre la línea general aprobada por el partido - la lucha por la paz es la "tarea central” de la línea planteada por el XI Congreso, dice acertadamente Valdés - y su efectivización por la militancia, las dificultades para llevarla a la práctica y la resistencia o grado de disidencia no expresado directamente por los integrantes de la organización sino por medio de las reticencias expresadas en la práctica de las actividades que se desprendían de la línea política. Se trataba, una vez más, de la consabida "traducción" de la línea a las actividades que de ella se desprendían. En el caso de no obtenerse éxito, la responsabilidad siempre recaía en los militantes que no habían

90 VALDÉs, “Traducir”, pp. 4-5. 
sabido aplicarla "creativamente", con entusiasmo, y no en los errores en su formulación. Una crítica que supusiera poner en duda la corrección de la línea significaba de inmediato la sospecha de una disidencia más profunda, la encarnación de una propuesta enemiga. La estabilidad de las direcciones, o de su núcleo fundamental, estaba fuera de toda duda.

\section{REFERENCIAS}

Alonso, Jorge

En busca de la convergencia. El Partido Obrero Campesino Mexicano, México, Centro de Investigaciones y Estudios Superiores en Antropología Social, 1990.

Alzaga, Óscar

"Mario Pavón Flores, testigo y protagonista del movimiento obrero”, en Alegatos, 67 (sep.-dic. 2007), pp. 399-430.

Amorós, Mario

Neruda, el príncipe de los poetas, Barcelona, Ediciones B, 2015, ed. digital, cap. 8, s. p. i. Consultado el 7 de enero de 2016. https://books.google.com.mx/books? id=v9rRCgAABAJ/ $\mathrm{pg}=\mathrm{PT} 276 / \mathrm{lpg}=\mathrm{PT} 276 / \mathrm{dq}$

Campa, Valentín

Mi testimonio. Memorias de un comunista mexicano, México, Ediciones de Cultura Popular, 1985.

CARR, Barry

"Hacia una historia de los comunismos mexicanos: desafíos y sugerencias”, en Concheiro, Modonesi y Crespo (coords.), 2011, pp. 575-580.

Claudín, Fernando

La crisis del movimiento comunista, t. 1, De la Komintern al Kominform, París, Ediciones Ruedo Ibérico, 1970. 
Codovilla, Victorio

La situación internacional y nacional a la luz del XIX Congreso del Partido Comunista de la Unión Soviética. Informe rendido ante el Comité Central del Partido Comunista de la Argentina (6, 7 y 8 de febrero de 1953), Buenos Aires, Anteo, 1953.

Comisión Nacional Organizadora del XiII Congreso

Boletín de discusión, núm. 1 (30 sep. 1959), México, reproducido en Concheiro y Payán, 2014, t. II, pp. 112-114.

Comité Central del Partido Comunista Mexicano

La lucha interna en el Partido durante los años de 1939 a 1948. Características principales, México, Ediciones de CP del CC del PCM, 1957.

Concheiro, Elvira, Massimo Modonesi y Horacio Crespo (coords.)

El comunismo: otras miradas desde América Latina, México, Universidad Nacional Autónoma de México, 2011.

Concheiro Bórquez, Elvira y Carlos Payán Velver (comps.)

Los congresos comunistas. México 1919-1981, México, Secretaría de Cultura del Gobierno del Distrito Federal, Centro de Estudios del Movimiento Obrero y Socialista (CEmos), 2014, 2 tomos.

Churchill, Rogers P. y William Slany (eds.), S. Everett Gleason (editor general)

Foreign Relations of the United States 1946, vol. vi, Eastern Europe, the Soviet Union, Washington, Department of State, Office of the Historian, Bureau of Public Affairs, United States Government Printing Office, 1969.

De Pablo Hammeken, Óscar

Entradas "Encina Rodríguez, Dionisio", "García Salgado, Andrés", "Manrique Arrevillaga, Blas", "Terrazas Guerrero, Manuel” y "Unzueta Lorenzana, Gerardo", en La Rojería. Diccionario biográfico de la izquierda mexicana, s. p. i.http:// 
es.scribd.com/doc/92646740/Diccionario-Biografico-de-laizquierda-socialistamexicana\#sribd. Consulta 10-11 de enero de 2016.

Deutscher, Isaac

Stalin. Biografía política, México, Era, 1965 [1 $1^{\mathrm{a}} \mathrm{ed}$. Oxford University Press, 1949].

Post Scriptum. Los últimos años de Stalin, Viento Sur. www. vientosur.info/documentos/Deutscher.pdf. Consulta $11 \mathrm{de}$ enero de 2016.

EnCINA, Dionisio

$X$ Congreso del Partido Comunista. Unidad democrática antiimperialista, por la soberanía de México, México, Ediciones del Fondo de Cultura Popular, 1947.

Sobre la situación política actual y las tareas de los comunistas mexicanos, México, Ediciones del Fondo de Cultura Popular, 1957.

Encina, Dionisio y J. Encarnación Valdés

Por la Paz, por la Democracia y la Independencia nacional. Partido Comunista Mexicano. Pleno del Comité Central Octubre 29, 30 y 31 de 1949. Informes y resolución, México, Fondo de Cultura Popular, 1950.

FERnández [Anaya], Jorge

"45 años al servicio de la causa del comunismo", en Teoría. Revista mensual del Comité Central del Partido Comunista Mexicano, 38-39 (sep. y oct. 1952), pp. 48-58.

Fernández Anaya, Jorge

"La fundación del Partido Comunista de El Salvador", en $M e$ moria, r:10 (mayo-jun. 1985), pp. 232-240.

Fernández Montes, Jorge Octavio

"Voces y llamamientos de la cultura por la paz. Génesis del pacifismo prosoviético de México en los albores de la Guerra 
Fría”, en Política y Cultura, 41 (ago. 2014), pp. 7-29, edición electrónica.

GADDIS, John Lewis

Strategies of Containment: A Critical Appraisal of American National Security Policy during the Cold War, Nueva York, Oxford University Press, 2005.

Gutiérrez, Pepe

Algunas notas sobre la represión del POUM en la zona republicana, Fundación Andreu Nin, edición digital, 2005. http:// www.fundanin.org/gutierrez16.htm. Consulta 13 de enero de 2016.

Jeifets, Lazar, Victor Jeifets y Peter Huber

La Internacional Comunista y América Latina, 1919-1943. Diccionario biográfico, Moscú, Instituto de Latinoamérica de la Academia de las Ciencias, Ginebra, Institut pour l'histoire du communisme, 2004.

Kennan, George

X [seudónimo], “The Sources of Soviet Conduct”, en Foreing Affairs, 25: 4 (jul. 1947).

Al final de un siglo. Reflexiones (1982-1995), México, Fondo de Cultura Económica, 1998.

Koestlen, Arthur

La escritura invisible, segundo volumen de su Autobiografía, Buenos Aires, Emecé, 1955 (1ª ed. en inglés, 1954).

López Díaz, Pedro

Economía política y crisis, México, Universidad Nacional Autónoma de México, 1989.

Marcou, Lilly

El movimiento comunista internacional desde 1945, Madrid, Siglo Veintiuno Editores, 1981 [1 $1^{a}$ ed., París, Presses Universitaires de France, 1980]. 
La Kominform, Madrid, Villalar, Colección Zimmerwald, 1978 [1 $1^{a}$ ed., Le Kominform, París, Presses de la Fondation Nationale des Sciences Politiques, 1977].

Martínez Verdugo, Arnoldo (ed.)

Historia del comunismo en México, México Grijalbo, 1983.

Maya Аmbía, Carlos

"Eugenio Varga: teórico de la crisis general del capitalismo", en López Díaz, 1989, pp. 171-ss.

Medvedev, Roy y Zhores

El Stalin desconocido, Barcelona, Crítica, 2005.

MÉndez, Alejo

“Por la renovación del partido”, en Martínez Verdugo (ed.), 1983, pp. 239-271.

Mesa Redonda de los marxistas mexicanos (1947)

Memoria integra, México, Centro de Estudios Filosóficos, Políticos y Sociales Vicente Lombardo Toledano, 1982.

Millon, Robert T.

Lombardo Toledano. Biografía intelectual de un marxista mexicano, México, Universidad Obrera de México Vicente Lombardo Toledano, 1976.

Nicolas, Claire

"Picasso en Varsovia. Compromiso y travesuras de un genio", en El Arca del Nuevo Siglo, año 9, 50 (jul. 2001). http://www. elarca.com.ar/. Consulta 6 de enero de 2016.

Olivares Briones, Edmundo

Pablo Neruda: los caminos de América. Tras las huellas del poeta itinerante III (1940-1950), Santiago de Chile, LOM, 2004. 


\section{Partido Comunista Mexicano}

"XI Congreso Nacional. México D. F. 20 al 25 de Noviembre de 1950. Convocatoria”, en Teoría, año II, $2^{a}$ época, núm. 16, pp. 31-37, reproducido en Concheiro y Payán, 2014, t. II, pp. 9-15.

XI Congreso Nacional. Resolución, México, Fondo de Cultura Popular, 1950, reproducido en Concheiro y Payán, 2014, t. II, pp. 15-42.

Peláez Ramos, Gerardo

"Guerra Fría, comunismo y sindicatos en México (19461950)”, www.lahaine.org. Consulta 11 de enero de 2016.

Powaski, Ronald E.

La Guerra Fría. Estados Unidos y la Unión Soviética, 19171991, Barcelona, Crítica, 2014 [1 $1^{\mathrm{a}}$ ed., The Cold War: The United States and the Soviet Union, 1917-1991, Oxford University Press, 1997].

Quintana, Mario

Del romanticismo al revisionismo. Superproducción, crisis y derrumbe del capitalismo, www.nodo50.org/gpm

RYAn, James G.

Earl Browder. The Failure of American Comunism, Tuscaloosa, The University of Alabama Press, 1997.

Sanhueza, Jorge

“Neruda 1949", en Anales de la Universidad de Chile (ene.dic. 1971), pp. 197-207.

Schidlowsky, David

Pablo Neruda y su tiempo: las furias y las penas, vol. 2, 19501973, Santiago de Chile, RiL Editores, 2008. 
Schмiтt, Karl M.

Communism in Mexico. A Study in Political Frustration, Austin, University of Texas Press, 1965.

Tarcus, Horacio (dir.)

Diccionario biográfico de la izquierda argentina, Buenos Aires, Emecé Editores, 2007.

Teitelboim, Volodia

Neruda, Santiago de Chile, Sudamericana, 1996.

Unzueta, Gerardo

"Crisis en el partido, crisis en el movimiento", en MARTíneZ Verdugo, 1983, pp. 189-238.

VALDÉs, J. Encarnación

"Traducir en luchas de masas la línea política del XI Congreso", en Teoría. Revista mensual del Comité Central del Partido Comunista Mexicano, año II, $2^{a}$ época (21 dic. 1950), pp. $1-34$.

Zhdánov, Andréi A.

Sobre la situación internacional, México, Fondo de Cultura Popular, 1947. 